\title{
A Model for the Evaporation of Biomass Pyrolysis Oil Droplets
}

\author{
W.L.H. Hallett $\mathrm{t}^{\mathrm{a},{ }^{*}}$ and N. A. Clark ${ }^{\mathrm{b}}$ \\ Departments of ${ }^{a}$ Mechanical Engineering and ${ }^{b}$ Chemical Engineering \\ University of Ottawa, Ottawa, Ontario, Canada K1N 1 C8
}

\begin{abstract}
This paper presents a numerical model for the evaporation and pyrolysis of a single droplet of pyrolysis oil derived from biomass. Continuous thermodynamics theory for multicomponent droplet evaporation is used, with the fuel being represented by four fractions: organic acids, aldehydes/ketones, water, and pyrolytic lignin, each of which is described by a separate distribution function. Pyrolysis of the lignin fraction is included, and detailed properties for all fractions are presented. The model is compared with the results of suspended droplet experiments, and is shown to give good predictions of the times of the major events in the lifetime of a droplet.
\end{abstract}

Keywords: Biomass pyrolysis oil; Droplet combustion; Droplet evaporation; Continuous thermodynamics.

${ }^{*}$ Corresponding author. E-mail address: hallett@genie.uottawa.ca (W.L.H. Hallett)

Accepted by Fuel, August 2005. 


\section{Nomenclature}

A surface area, $\mathrm{m}^{2}$

c molar density, $\mathrm{kmol} / \mathrm{m}^{3}$

$\mathrm{C}_{\mathrm{P}} \quad$ specific heat, $\mathrm{kJ} / \mathrm{kmol} \mathrm{K}$

$\mathrm{C}_{\mathrm{PG}} \quad$ vapour phase specific heat as used in eq. (14)

D diffusivity, $\mathrm{m}^{2} / \mathrm{s}$

E activation energy, $\mathrm{kJ} / \mathrm{mol}$

$\mathrm{h}_{\mathrm{fg}} \quad$ enthalpy of vaporization, $\mathrm{J} / \mathrm{kmol}$

I distribution variable $=$ species molecular mass, $\mathrm{kg} / \mathrm{kmol}$

$\mathrm{J} \quad$ number of fuel distribution functions

$\mathrm{K}$ pre-exponential

L lignin fraction unconverted

M mol mass, $\mathrm{kg} / \mathrm{kmol}$

$\mathrm{N} \quad \operatorname{mol}$ flux, $\mathrm{kmol} / \mathrm{m}^{2} \mathrm{~s}$

$\mathrm{R}$ droplet radius, $\mathrm{m}$; universal gas constant

$\mathrm{T}$ temperature, $\mathrm{K}$

$\mathrm{v}^{*} \quad$ molar average velocity, $\mathrm{m} / \mathrm{s}$

$\mathrm{V} \quad$ volume, $\mathrm{m}^{3}$

w mass fraction in liquid

x mol fraction in liquid

y mol fraction in vapour 
$\gamma \quad$ distribution origin, $\mathrm{kg} / \mathrm{kmol}$

$\zeta_{\mathrm{C}} \quad$ fraction of lignin converted to char

$\theta$ distribution mean (= mean mol mass), $\mathrm{kg} / \mathrm{kmol}$

$\lambda$ thermal conductivity, $\mathrm{W} / \mathrm{mK}$

$\chi_{\mathrm{G}} \quad$ ratio $\mathrm{N}_{\mathrm{G}} /$ total mol flux $\mathrm{N}$

$\chi_{\mathrm{j}} \quad$ ratio $\mathrm{N}_{\mathrm{j}}$ /total vapour mol flux

$\sigma \quad$ distribution standard deviation, $\mathrm{kg} / \mathrm{kmol}$

$\Psi \quad=\theta^{2}+\sigma^{2}(2$ nd moment $)$

\section{Subscripts}

A air

C char

F fuel

G pyrolysis gas

j index for a fuel fraction

L liquid phase

$\mathrm{P} \quad$ pyrolysis reaction

PY pyrolyzing component

$\mathrm{R} \quad$ at droplet surface

$0 \quad$ initial value

$\infty \quad$ ambient value 


\section{Introduction}

Biomass pyrolysis oils produced by the pyrolysis of wood wastes, bark or other biomass materials exhibit complex evaporation and combustion behaviour. Typically the initial liquid heating period is followed by bubbling and/or "micro-explosions", after which the heavy non-volatile residue remaining pyrolyzes to a highly porous, irregularly-shaped char particle or "cenosphere" [1-4]. Although the chemistry of these fuels and their application in engines has been the object of a number of studies, no attempt has been made to model the processes of their combustion. This paper therefore presents a model for the evaporation of a single droplet of biomass pyrolysis oil, using the principles of continuous thermodynamics to approximate the complex multicomponent nature of the real fuel as a series of probability density functions representing the main chemical groups present: acids, aldehydes, water and pyrolytic lignin. The model includes pyrolysis of the lignin component to char after the volatile components have been evaporated. The predictions are compared with observations from experiments using the suspended droplet technique.

The chemistry of pyrolysis oils is qualitatively well known, although detailed quantitative compositions are usually not available. The main components are organic acids, aldehydes, ketones, phenols, anhydrosugars such as levoglucosan, pyrolytic lignin (comprising guaiacyl- and syringylbased fragments of the original lignin polymer) and substantial quantities of water, typically $25 \%$ [5-22]. Usually only trace amounts of hydrocarbons are present, the vast majority of the components being oxygenates. These fuels are typically denser and more viscous than petroleum fuels, with a specific gravity typically around 1.2 [5,6,10,22-25]. The chemical composition may change over time owing to "aging", in which light components are polymerized [18, 26, 27], and phase separation is also possible [6, 7]. Studies of the combustion behaviour of single droplets have been performed 
on free-falling droplets in drop tube furnaces [1-4] as well on suspended droplets [4], and have established the sequence of combustion events described earlier. Combustion tests have also been performed in gas turbine combustors and Diesel engines [22, 28].

\section{Numerical Model}

The model developed here describes the evaporation of the droplet and its pyrolysis to gas and char. Combustion is not included. Given the large number of compounds present in a typical pyrolysis oil and the lack of complete information on its composition, it was decided to use a multidistribution "continuous thermodynamics" technique to describe the fuel. Continuous thermodynamics represents complex mixtures by probability density functions rather than by discrete components, so that the distribution parameters rather than individual species concentrations are solved for in transport and balance equations. The theory required to deal with droplet evaporation using this technique was developed in earlier work, initially only for a single distribution function $[29,30]$. Pyrolysis oil contains several chemical compound families with quite different properties, and it is therefore appropriate to describe it by assigning each chemical family a separate distribution function. The theory required for multiple distribution functions was developed recently [31]; it is here simplified by assuming a quasi-steady gas phase and uniform (but time-varying) properties to achieve an analytical vapour-phase solution similar to "classical" droplet evaporation theory, much as was done for a single distribution in [30].

\subsection{Vapour Phase Equations}

The liquid is assumed to contain $J$ different chemical families, each represented by a liquid 
phase distribution function $f_{L j}(I)$ with mean $\theta_{L j}$ and variance $\sigma_{L j}{ }^{2}$. Evaporation produces corresponding vapour phase distributions $f_{j}(I)$, each with parameters $\theta_{j}$ and $\sigma_{j}^{2}$. The vapour and liquid phase mol fractions of a particular species are then

$$
y_{i}=y_{F j} f_{j}(I) d I ; \quad x_{i}=x_{F j} f_{L j}(I) d I
$$

where $y_{F j}$ and $x_{F j}$ are the overall mol fractions of distribution $j$ in the vapour and liquid and the distribution variable $I$ is the species molecular weight. The $y_{F j}$ together with the ambient air and pyrolysis gas mol fractions $y_{A}$ and $y_{G}$ sum to 1 . Transport equations for each distribution in the vapour phase can be derived by substituting $y_{i}$ from Eq. (1) into the diffusion equation and integrating over the distribution with different powers of $I$ as described in earlier work [29, 30], yielding

$$
\begin{aligned}
& r^{2} c v^{*} \frac{\partial y_{F j}}{\partial r}=c \bar{D}_{j} \frac{\partial}{\partial r}\left(r^{2} \frac{\partial y_{F j}}{\partial r}\right) \\
& r^{2} c v^{*} \frac{\partial \phi_{j}}{\partial r}=c \bar{D}_{j} \frac{\partial}{\partial r}\left(r^{2} \frac{\partial \phi_{j}}{\partial r}\right)
\end{aligned}
$$

where $c$ is the molar density, $v^{*}$ is the molar average velocity, $\bar{D}_{j}$ is a mean diffusivity as defined in [29] and $\phi_{\mathrm{j}}$ represents either $\left(y_{F j} \theta_{\mathrm{j}}\right)$ or $\left(y_{F j} \Psi_{\mathrm{j}}\right)$, where $\Psi=\theta^{2}+\sigma^{2}$ is the second central moment. Spherical symmetry with transport in the radial direction only has been assumed. The boundary conditions are values of $y_{F j},\left(y_{F j} \theta_{\mathrm{j}}\right)$, and $\left(y_{F j} \Psi_{\mathrm{j}}\right)$ at the surface and in the ambient. The mol flux $N$ leaving the surface is related to $v^{*}$ and the droplet radius $R$ by continuity:

$$
c v^{*} r^{2}=N R^{2}
$$

One of the chemical groups in the liquid is assumed to comprise high molecular weight 
species, mainly representing pyrolytic lignin. For brevity, this will be referred to as "lignin" throughout this paper, although it is actually the decomposition products of the original wood lignin rather than true lignin. This "lignin" component vaporizes very little, and therefore remains liquid at higher temperatures, where it is assumed to pyrolyze, producing gas and char. $N$ will therefore include pyrolysis gas as well as vapour. The mol fraction of each vapour component and of pyrolysis gas in the total mol flux are defined respectively as

$$
\chi_{j}=N_{j} / N ; \quad \chi_{G}=N_{G} / N
$$

where

$$
\sum_{j=1}^{J} \chi_{j}+\chi_{G}=1
$$

Eq. (2) and (4) may then be solved for the total mol flux $N$ :

$$
N=\frac{c \bar{D}_{j}}{R} \ln \left(1+B_{j}\right) ; \quad B_{j}=\frac{y_{F j R}-y_{F j \infty}}{\chi_{j}-y_{F j R}}
$$

where subscripts $R$ and $\infty$ refer to values at the droplet surface and in the surroundings respectively. This is identical to the classical solution for droplet vaporization [32] except for the definition of the transfer number $B_{j}$, and also similar to analyses for mixtures of pure components such as references $[33,34]$. Like these solutions, eq. (7) may be generalized to include the effects of convection by introducing the Sherwood number at low mass transfer rates $S h_{0}[30,32]$ :

$$
N=\frac{c \bar{D}_{j} S h_{0}}{2 R} \ln \left(1+B_{j}\right)
$$

The $\chi_{\mathrm{j}}$ 's may be found by writing Eq. (7) for $j=1$ and for $j$ and equating, giving 


$$
\chi_{j}=y_{F j R}+\frac{y_{F j R}-y_{F j \infty}}{\left(1+B_{1}\right)^{\bar{D}_{1} / \bar{D}_{j}}-1}=y_{F j R}+\frac{y_{F j R}-y_{F j \infty}}{\exp \left(2 N R / c \bar{D}_{j} S h_{0}\right)-1}
$$

Eq. (6-9) together with the reaction rate expression for $N_{G}$ (given later) give $J+2$ equations which can be solved for the $\chi_{j}$ 's, $\chi_{\mathrm{G}}$ and $N$. Eq. (2) and (3) can be solved for the variation of $y_{F j}$ and $\phi_{j}$ in the vapour phase:

$$
\begin{gathered}
y_{F j}(r)=\chi_{j}-\left(\chi_{j}-y_{F j \infty}\right)\left(1+B_{j}\right)^{-Z} \\
\phi_{j}(r)=\phi_{j R}-\frac{1}{B_{j}}\left(\phi_{j R}-\phi_{j \infty}\right)\left[\left(1+B_{j}\right)^{(1-Z)}-1\right]
\end{gathered}
$$

where the coordinate $Z$ is

$$
Z=1+\left(S h_{0} / 2\right)[(R / r)-1]
$$

The vapour phase energy equation is as given in [29,30], and is solved as in [30] to give the heat transfer to the droplet:

$$
q=\frac{N u_{0} \lambda}{2 R} \frac{\ln \left(1+B_{T H}\right)}{B_{T H}}\left(T_{\infty}-T_{R}\right)
$$

where

$$
B_{T H}=\exp \left(2 N C_{P G} R /\left(\lambda N u_{0}\right)-1\right.
$$

$N u_{0}$ is the Nusselt number at low mass transfer rates, $\lambda$ is the vapour phase thermal conductivity, and $C_{P G}$ is a gas phase specific heat which includes fuel vapour and pyrolysis gases but not the ambient air. By defining $C_{P G}$ in this fashion the interdiffusion term in the energy equation is included in the solution [30]. Details of property calculations are given in the Appendix. 


\subsection{Liquid Phase Equations}

The liquid is assumed to be well-mixed - uniform in composition and temperature - allowing its behaviour to be described by simple overall balances. Although the viscous nature of this fuel may restrict internal circulation more than in hydrocarbons, the vigorous bubbling observed during much of the evaporation process will produce substantial mixing. The "lignin" component in addition to evaporating is assumed to pyrolyze in a one-step first order reaction, each $\mathrm{kg}$ of lignin producing $\zeta_{\mathrm{C}} \mathrm{kg}$ of char and $\left(1-\zeta_{\mathrm{C}}\right) \mathrm{kg}$ of gas. The reaction rate is described by

$$
\frac{d L}{d t}=-K L \exp (-E / R T)
$$

where $L$ is the fraction of original lignin unconverted. Because a small amount of the lignin can evaporate, $L$ must be defined as

$$
L=\frac{\text { mass of lignin }}{\text { mass of lignin }+ \text { mass of lignin already converted to char }}
$$

where the second term in the denominator is used to exclude any lignin which has evaporated from the original lignin mass used to define $L$. Eq. (16) reduces to

$$
L=\left[1+\frac{M_{C} c_{C} V_{C}}{x_{P Y} \theta_{L P Y} \zeta_{C} c_{L} V_{L}}\right]^{-1}
$$

where $V_{L}$ and $V_{C}$ are the volumes of liquid and char, $c_{L}$ and $c_{C}$ are the corresponding molar densities, $x_{P Y}$ is the mole fraction of pyrolyzing component (lignin) in the liquid, $\theta_{L P Y}$ is the mean of the lignin distribution function (ie the average molecular weight) and $M_{C}$ is the molecular weight of char. The mole flux of pyrolysis gas is then 


$$
N_{G}=\frac{\left(1-\zeta_{C}\right)}{A \theta_{G}}\left[x_{P Y} \theta_{L P Y} c_{L} V_{L}+M_{C} c_{C} V_{C} / \zeta_{C}\right] \frac{d L}{d t}
$$

where the quantity in brackets is the original lignin mass excluding that which has evaporated (the denominator in Eq. 16), $\mathrm{A}$ is the surface area, and $\theta_{\mathrm{G}}$ the mean mol mass of the pyrolysis gases. Mol balances on the droplet yield the rate of conversion of liquid by evaporation (first term) and pyrolysis (second term), and the rate of production of char:

$$
\begin{gathered}
\frac{d}{d t}\left(c_{L} V_{L}\right)=-N A\left[\left(1-\chi_{G}\right)+\frac{\chi_{G}}{\left(1-\zeta_{C}\right)} \frac{\theta_{G}}{\theta_{L P Y}}\right] \\
\frac{d}{d t}\left(c_{C} V_{C}\right)=N A\left[\frac{\chi_{G} \zeta_{C}}{\left(1-\zeta_{C}\right)} \frac{\theta_{G}}{M_{C}}\right]
\end{gathered}
$$

These are combined to track the total droplet volume and diameter. A mol balance on the droplet for a single species $i$ gives

$$
\frac{d}{d t}\left(x_{i} c_{L} V_{L}\right)=-N_{i} A-N_{P i} A
$$

where the first term represents evaporation and the second is the rate of pyrolysis of species $i$ if applicable. The vapour flux $N_{i}$ can be written as:

$$
N_{i}=N y_{i R}-\left.c D_{i} \frac{\partial y_{F i}}{\partial r}\right|_{R}
$$

This is substituted in Eq. (21), distribution functions are introduced (Eq. 1), the resulting expression is integrated over the distribution variable $I$ as detailed in $[29,30]$, and the derivative in Eq. (22) is evaluated from Eq. (10). The result is an expression for the variation of the liquid composition with time. For a fuel fraction which does not pyrolyze, $N_{P i}$ is omitted, giving 


$$
\frac{d x_{j}}{d t}=\frac{N A}{c_{L} V_{L}}\left[x_{j}\left(1-\chi_{G}\right)-\chi_{j}+\frac{x_{j} \chi_{G}}{\left(1-\zeta_{C}\right)} \frac{\theta_{G}}{\theta_{L P Y}}\right] ; j \neq P Y
$$

For the pyrolyzing ("lignin") fraction, the pyrolysis rate of a single component can be assumed to be given by that for the whole fraction multiplied by a distribution function $f_{P}(I)$, such that

$$
N_{P i}=\frac{\chi_{G} N}{\left(1-\zeta_{C}\right)} \frac{\theta_{G}}{\theta_{L P Y}} f_{P}(I) d I
$$

in which case the composition change becomes

$$
\frac{d x_{P Y}}{d t}=\frac{N A}{c_{L} V_{L}}\left[x_{P Y}\left(1-\chi_{G}\right)-\chi_{P Y}+\frac{\left(x_{P Y}-1\right) \chi_{G}}{\left(1-\zeta_{C}\right)} \frac{\theta_{G}}{\theta_{L P Y}}\right]
$$

Performing the same procedure with a weighting factor of $I$ in the integration gives an expression for the liquid distribution means:

$$
\begin{gathered}
\frac{d}{d t}\left(x_{j} \theta_{L j}\right)=\frac{N A}{c_{L} V_{L}}\left[x_{j} \theta_{L j}\left(1-\chi_{G}\right)-y_{F j R} \theta_{j R}+\left.\frac{c \bar{D}_{j}}{N} \frac{\partial}{\partial r}\left(y_{F j} \theta_{j}\right)\right|_{R}+\right. \\
\left.+\left(x_{j} \theta_{L j}-\theta_{P}\right) \frac{\chi_{G}}{\left(1-\zeta_{C}\right)} \frac{\theta_{G}}{\theta_{L P Y}}\right]
\end{gathered}
$$

It is reasonable to assume that $f_{P}(I)$ is identical with the liquid distribution function $f_{L}(I)$ (in other words, all components of the lignin fraction pyrolyze at the same rate), so that $\theta_{\mathrm{p}}=\theta_{\mathrm{LPY}}$. Expanding Eq. (26) and substituting Eq. (25) then yields

$$
\frac{d \theta_{L j}}{d t}=\frac{N A}{x_{j} c_{L} V_{L}}\left[\chi_{j} \theta_{L j}+\frac{\theta_{j \infty} y_{F j \infty}-\theta_{j R} y_{F j R}\left(1+B_{j}\right)}{B_{j}}\right]
$$

while a similar equation holds for the liquid second moments $\Psi_{L j}$. These are the same whether the component in question pyrolyzes or not.

The total volume $V$ of the droplet at any time comprises the liquid and char volume, and its 
change during a time step can be written as

$$
\frac{d V}{d t}=\frac{1}{c_{L}} \frac{d}{d t}\left(c_{L} V_{L}\right)-\frac{V_{L}}{c_{L}} \frac{d c_{L}}{d t}+\frac{1}{c_{C}} \frac{d}{d t}\left(c_{C} V_{C}\right)
$$

assuming that the char specific volume $c_{C}$ is constant. The first and last terms are obtained from Eq. (19) and (20), while the middle term can be shown to be

$$
\frac{V_{L}}{c_{L}} \frac{d c_{L}}{d t}=-\frac{V_{L}}{\theta_{L}} \frac{d \theta_{L}}{d t}-V_{L} \alpha_{P} \frac{d T_{L}}{d t}
$$

where the isobaric thermal expansion coefficient is defined by

$$
\alpha_{P}=-\frac{1}{\rho_{L}}\left(\frac{\partial \rho_{L}}{\partial T}\right)_{P}
$$

and use has been made of the fact that the mass density $\rho_{L}=c_{L} \theta_{L}$. The expansion coefficient was taken as $8 \cdot 10^{-4} \mathrm{~K}^{-1}$ based on data given by Boucher et al. [17] and Peacocke et al. [23]. The mass density of the char is assumed to be $\zeta_{\mathrm{C}}$ times the density of the lignin fraction - in other words, no volume change occurs in pyrolysis.

Droplet heating is described by an energy balance on the droplet, as in earlier work [29, 30]:

$$
\frac{d T_{L}}{d t}=\frac{3}{c_{P L} c_{L} R}\left(q-N h_{f g}\right)
$$

Calculation of the enthalpy of vaporization $h_{f g}$ is discussed in the Appendix. Phase equilibrium is described by a continuous form of Raoult's law with the Clausius-Clapeyron equation for individual species vapour pressures $[29,30]$. The assumption of ideal mixture behaviour is questionable for the polar compounds in pyrolysis oil, but in view of the uncertainties in liquid composition and the complexity of more accurate models it is a reasonable approximation. The enthalpy of pyrolysis is 
assumed to be zero. Other features of the model are as described in earlier papers [29, 30], and calculations included radiation from furnace walls and natural convection heat and mass transfer at the droplet [30]. The time step for numerical integration of the equations was chosen so that roughly 400 time steps were required to complete evaporation and pyrolysis.

\subsection{Fuel Properties}

Complete chemical analyses for these fuels are not available: most composition information in the literature is in the form of mass fractions of selected components $[5,8,10,13,19,20,21,22]$, mass fractions of groups (e.g. water-solubles and -insolubles) $[5-8,15,16]$, or listings of components without quantitative concentrations $[5,7,8,10,11,14,16,19]$. The composition used for model calculations here is therefore a representative one based on typical information from a number of researchers, and does not pretend to be an accurate model of a particular product. It is summarized in Table 1. The fuel was assumed to comprise four chemical groups: organic acids, aldehydes and ketones, pyrolytic lignin (lignin decomposition products: phenols, guaiacyl- and syringyl-based compounds, and lignin oligomers), and water. Most pyrolysis oils also contain around $10 \%$ of heavier cellulose decomposition products such as levoglucosan and cellobiose [5,7,10, 13, 22]; these are considered to be a pyrolyzing component and lumped in with the lignin fraction. All fractions were represented by gamma distributions as in earlier work $[29,30]$ with distribution parameters as given in Table 1. The distributions are shown in Fig. 1. The distribution functions for acids and aldehydes were chosen so as to span the molecular weight range of the most frequently encountered compounds: from formic to hexanoic acid for the acid group, with a peak around acetic acid, and from acetaldehyde to 1-hydroxy-2-butanone for the aldehyde/ketone group, with a peak between 
hydroxyacetaldehyde and hydroxypropanone. The lignin distribution was approximately fitted to an experimental one given by Scholze et al. [12]; similar distributions are given by others [8, 26, 27]. The exact distribution function used for lignin is of little importance, because so little of this component evaporates. Water, as a pure component, is represented by a very narrow distribution. The number mean and mass mean molecular weights of the oil of Table 1 as a whole are 52 and 361 respectively; the latter figure is in the range of those reported by others $[6,18,22,27]$.

Continuous mixture models require correlations for the properties of each fraction as functions of molecular weight and temperature. Simple correlations of the forms given in [29] were developed for the four chemical groups by using standard property prediction methods as detailed in the Appendix. The density of the char formed by pyrolysis was set to $\zeta_{\mathrm{C}}$ times that of the parent lignin fraction, and its specific heat determined according to Merrick [35]. Gaseous products of pyrolysis gas generally contained large proportions of $\mathrm{CO}, \mathrm{CO}_{2}$ and $\mathrm{H}_{2} \mathrm{O}$ as well as smaller quantities of light hydrocarbons and other species. Carbon dioxide was taken as a representative species of this group, and the pyrolysis gas assigned the properties of $\mathrm{CO}_{2}$.

Rate parameters are required for the pyrolysis reaction (Eq. 15). The literature gives a vast range of rates for biomass pyrolysis: for lignin, activation energies ranging from 20 [36] to 46 [37] to 250 [38] kJ/mol have been given, while for cellulose recent studies have cited $E=120$ to 210 [39] $\mathrm{kJ} / \mathrm{mol}$. For this work rate parameters $E=200 \mathrm{~kJ} / \mathrm{mol}, A=1.0 \cdot 10^{15} \mathrm{~s}^{-1}$ were selected based on the amount of residue remaining after experiments at different temperatures (see later). These data also gave the char yield from pyrolysis as $\zeta_{\mathrm{C}}=0.6$. 


\section{Experiments}

The model was tested against experiments conducted on single droplets using the suspended droplet/moving furnace technique, with apparatus as described in [40]. Droplets of $1.4-1.7 \mathrm{~mm}$ diameter were placed on the end of a quartz fibre and a preheated electric furnace moved to rapidly enclose the droplet and begin evaporation. A video camera and optical system recorded droplet behaviour, and droplet diameters were measured from individual images, since the viscous and sticky nature of the fuel made precise control of droplet size difficult. A nitrogen atmosphere was used in the furnace to suppress combustion and ensure pure evaporation, thus more nearly simulating conditions in spray combustion, where droplets evaporate in a vapour cloud rather than burning individually. Other experiments conducted on biomass pyrolysis oils to date have examined single droplet combustion rather than evaporation [1-4], and hence are not directly comparable with either these experiments or the results of the present model.

The suspended droplet technique has the advantage that the droplet is stationary and hence easily observed, something that is much more difficult with the falling droplets in a drop tube furnace. The quartz fibre is similar in thermal conductivity and specific heat to liquid fuels, and is therefore not expected to affect droplet heating significantly, but it could conceivably act as a nucleation site for internal boiling, and this issue will be examined later. For some experiments, a fine wire thermocouple $(0.127 \mathrm{~mm}$ wire, type $\mathrm{K})$ was used as the droplet suspension instead in order to record liquid temperatures. The model and the experimental technique were tested against each other by recording diameter versus time histories for quartz fibre-supported droplets of pure $n$ dodecane and comparing these to predictions for the same fuel. When radiation and natural convection heat transfer were included, excellent agreement with measurements was obtained. 


\section{Results and Discussion}

\subsection{Droplet History}

Video recordings of droplet behaviour showed similar phenomena to those observed by others [1-4], and Figs. 2 - 4 summarize these observations as time lines. After an initial heating period in which no significant change was observed, the droplet underwent vigorous bubbling and disruption, swelling to about twice its original diameter and collapsing again around 4-5 times per second. (Other writers have referred to "microexplosions" [1-4], but the bubbling in the present experiments was not violent enough to warrant this name, and did not discharge material from the droplet.) With time the liquid became more viscous and the droplet surface appeared to "skin over"; this progressively restricted bubbling, leading to a quieter period in which the droplet no longer bubbled but still moved around erratically on the fibre. This suggests polymerization of the liquid, which is known to occur with these fuels $[6,9,18,26,27]$. When motion stopped altogether the droplet had become a largely solid char "cenosphere" of irregular and highly porous shape.

Figs. 2 - 4 compare the predicted droplet composition and temperature histories with the experimental timelines. The light components - acids, aldehydes, and water - evaporate simultaneously, and during this period the temperature remains nearly constant, indicating something approximating an equilibrium vaporization state. The slight rise in temperature that does occur results from fractional distillation of the acid and aldehyde groups as they evaporate: light fractions are preferentially vaporized, leaving a narrower, predominantly heavy distribution behind. This causes the distribution means to rise and the standard deviations to fall with time (Fig. 5). However, water dominates the process thermally because of its very high enthalpy of vaporization, and this constrains the temperature to remain close to the boiling point of water until the volatile components 
have evaporated. The lignin remaining evaporates very little because of its high molecular weight, so that the temperature then rises sharply and pyrolysis begins, converting lignin to char and gas.

Comparing model and experiment, the period of evaporation of the volatile components agrees well with the observed bubbling and disruption period, confirming that this behaviour results from evolution of light species. Only for the lowest temperature is the predicted volatile evaporation time significantly less than the observed bubbling period (Fig. 4). A possible explanation for this anomaly lies in a conversion of some light species to heavier fractions through polymerization, which would reduce evaporation rates and prolong bubbling. Since the droplet temperatures during the bubbling period are very similar regardless of the ambient temperature, polymerization will proceed at roughly the same rate in all cases; however, because of slow evaporation at low temperatures, the time available is much longer, and the degree of polymerization will therefore be larger.

Fig. 6 represents gas and vapour evolution rates from the droplet for the conditions of Fig. 3 , presented as droplet volumes per second to allow rough comparison with bubbling. From visual observations of the bubbling rate (4-5 per second) and bubble volume, the vapour flux associated with the bubbles was estimated at roughly 20 droplet volumes/sec. The fluxes in Fig. 6 are substantially larger, suggesting that most evaporation still takes place from the droplet surface. The onset of bubbling clearly coincides with the point at which the temperature first reaches its equilibrium value (Fig. 3); this is also the point at which the rate of evolution of vapour is highest because the fuel is still rich in light components. Lower bubbling rates later on correspond to reduced vapour production rates because of the removal of light components, although the ongoing polymerization of the fuel, as indicated by the increasingly viscous nature of the surface, would also 
be expected to decrease vapour pressures.

Internal boiling in a droplet indicates differences in composition between the surface and the interior, with the surface layer being depleted of lighter components and therefore capable of being heated to a higher temperature. This state of affairs usually indicates a low rate of mixing in the liquid, but in fact one would expect the bubbling to produce fairly vigorous mixing. A more likely explanation is that polymerization of the surface layer prevents vapour from escaping, and the degree to which the "skin" of the bubbles was observed to stretch before the bubbles burst supports this. Related to this is the question of whether the liquid becomes superheated before bubbling begins. As mentioned earlier, the supporting fibre in the present experiments makes this unlikely: it will probably provide nucleation sites and ensure that boiling occurs at the bubble point of the mixture. With free-falling droplets, however, superheat should be possible, and this may explain why fairly violent microexplosions are observed in drop tube furnace experiments [1-4] but not in the present work. Microexplosion would appear to preclude bubbling, in which case the amount of mixing in free droplets would be expected to be less.

To further investigate the possibility of superheating, some experiments were conducted with a $0.127 \mathrm{~mm}$ diameter thermocouple as the suspending fibre (Fig. 7). Calibration experiments with pure $n$-dodecane droplets showed that even with fine wire thermocouples the heat conducted into the droplet through the lead wires was substantial, resulting in shorter vaporization times and recorded temperatures that were $30-40^{\circ} \mathrm{C}$ higher than calculated equilibrium vaporization temperatures for $n$-dodecane. A simple correction was devised to account for this enhanced heat transfer in the model, but it only corrected the heating rate (i.e. the time scale) and not the measured temperatures. If the $30-40^{\circ}$ error in recorded temperatures is subtracted, then the measured 
temperatures in Fig. 7 agree fairly well with the predicted ones, and are well below the predicted bubble points of the mixture - no superheating occurs before bubbling, in other words.

\section{2 Residues}

Measurements of the residue mass remaining after evaporation were used to estimate the pyrolysis rate parameters and the char yield $\zeta_{\mathrm{C}}$ (Fig. 8). At high temperatures the residues were clearly char (carbon) "cenospheres", irregular, porous and friable; their mass did not vary with temperature, and was used to deduce that $\zeta_{\mathrm{C}}=0.6$. At low temperatures the mass was much greater, and the residue had a completely different appearance, being round, smooth and glossy, with a somewhat porous interior and a surface increasingly "sticky" to the touch as the exposure temperature dropped. These residues had clearly not pyrolyzed, but had simply dried out, leaving unconverted lignin and perhaps additional material from polymerisation of light fractions. To gain insight into the processes occurring here, some of these droplets were withdrawn from the furnace and weighed just after bubbling had ceased, while others were left in the furnace for five times as long ("long term exposure" in Fig. 8). At $573 \mathrm{~K}$ and lower temperatures the residue fraction is larger than the char yield and does not change with increasing exposure. However, at $673 \mathrm{~K}$ it is initially equal to that at $573 \mathrm{~K}$ and then drops to the char value with longer exposure, indicating that pyrolysis occurs slowly at $673 \mathrm{~K}$ but does not occur at all at $573 \mathrm{~K}$. This observation together with the time scales for pyrolysis from the experiments was used to roughly choose the rate parameters. The activation energy selected $(E=200 \mathrm{~kJ} / \mathrm{mol})$ is at the upper end of the range given by the literature [36-39], but lower values such as the $50 \mathrm{~kJ} / \mathrm{mol}$ used by Grønli et al. [37] gave excessively long pyrolysis times at high temperature or too rapid pyrolysis at low temperature, depending on the value 
of pre-exponential $K$ used. Since the "lignin" in pyrolysis oil is chemically different from the lignin in wood, it is not surprising that its decomposition kinetics should be different. Model predictions of residue in Fig. 8 show that the chosen rate parameters give reasonable agreement with the measured trends.

The residue at the end of the bubbling process at $473-673 \mathrm{~K}$ is evidently approximately equal to the lignin mass; it confirms the lignin quantity chosen to model the fuel (Table 1) and in fact could be used to fit it. However, at the lowest temperature (393 K in Fig. 8) the residue mass is greater still, suggesting that polymerization of light components is now proceeding more quickly than vaporization and adding to the high molecular weight residue. Since the model does not include polymerization, it cannot predict this behaviour. These low temperature experiments are probably irrelevant to droplet behaviour under combustion conditions, but they do give insights into processes which are much more difficult to observe at higher temperatures.

\subsection{Model Behaviour}

Since detailed composition information is difficult to obtain for these fuels, it is of interest to consider how sensitive droplet evaporation is to the assumed fuel composition. Figs. 9 and 10 explore the effects of variations in composition. As in Fig. 2 - 4, the rise in temperature after equilibrium vaporization indicates the point at which the volatile species have disappeared (Fig. 9), while the plateau in the mass history represents the heating period before pyrolysis begins (Fig. 10). Raising the acid fraction from 10 to $20 \%$ (case A) increases the amount of volatile liquid which must be evaporated and therefore delays the onset of pyrolysis. This effect is small because the enthalpy of vaporization of the acid is low and little additional heat transfer is required to vaporize the extra 
liquid. The same conclusion can be reached for the aldehyde fraction, which is similar enough in behaviour and properties to the acids that one could probably simplify the model by combining them. However, if the same change is made in the water fraction (case B) the much higher enthalpy of vaporization slows evaporation and delays the start of pyrolysis substantially. Case $\mathrm{C}$ tests the sensitivity to the properties of one of the light fractions by doubling the $\theta_{\mathrm{L}}$ and $\sigma_{\mathrm{L}}$ of the aldehyde group distribution function. This delays its evaporation till the lighter water and acid fractions are gone, reducing the average evaporation rate (Fig. 10), but producing an earlier temperature rise as the aldehydes undergo fractional distillation (Fig. 9). Despite the fact that this is a very substantial change in properties, its effects are fairly modest. None of these changes except that to the water fraction affects the overall droplet lifetime significantly, and it can therefore be concluded that the water content is the single most important determinant of evaporation behaviour. Fortunately, this does not vary greatly most pyrolysis oils reported in the literature $[2,5,6,8,10,13,15,17,22,28]$, in part because water concentrations over $25 \%$ may cause phase separation $[6,10]$. In all cases the equilibrium vaporization temperature is practically the same, because the high enthalpy of vaporization of water causes it to dominate the process thermally; liquid temperatures during evaporation would therefore vary little between different fuels. The lignin fraction, which has been reduced in cases $\mathrm{A}$ and $\mathrm{B}$ to accomodate the extra light components, is essentially inert as far as evaporation is concerned, and its distribution function has no significant influence. However, the lignin fraction will of course directly govern the mass of char produced and hence the subsequent char burnout time.

Pyrolysis oils may be diluted with methanol to make them easier to atomize or to reduce aging effects $[1,17,18,26,28]$. The effects of doing this were simulated by adding $10 \%$ methanol 
as a fifth component to the fuel of Table 1. The pure methanol was modelled using a distribution function with $\theta_{\mathrm{L}}=32, \sigma_{\mathrm{L}}=1, \gamma=30$. Fig. 11 shows that this has very little effect on droplet lifetime: the methanol is slightly more volatile than the other light components of the fuel, and hence evaporates more quickly, so that the overall time to vaporize the light components changes very little in spite of their greater mass. It has been shown, however, that for free droplets methanol may make microexplosion occur more quickly [1].

The calculations so far have been made with large droplets as in the experiments. Fig. 12 compares the evaporation history of Fig. 2 with that for a droplet size more typical of spray combustion. Simple droplet evaporation theory states that the time should scale as diameter squared [30, 32], and Fig. 12 shows that this scaling gives essentially identical sequences of events for the initial heating and evaporation stages. During the subsequent lignin pyrolysis period the heat transfer scales with $d^{2}$ but the chemical reaction does not, so that the temperature histories agree but not the progress of pyrolysis. This comparison is made without convection or radiation heat transfer, since both of these cause some departure from $d^{2}$ scaling.

\section{Conclusions}

The model presented here includes most of the processes that a droplet of biomass pyrolysis oil undergoes in spray combustion (except for the burnout of the char residue), and includes the main features of the chemistry and physical properties of the fuel. It has been shown to give reasonable predictions of the time scales of the major events in the life of a droplet: initial heating, evaporation of volatile species, and pyrolysis of pyrolytic lignin to char. The bubbling or internal boiling of the droplet as volatile species are evolved is not modelled explicitly, but the good agreement of predicted 
and measured times suggests rather surprisingly that bubbling does not much affect the overall rate of heat transfer to the droplet. Given that exact detailed composition information is rarely available for these fuels, it is fortunate that the model results are not very sensitive to the details of the distribution functions assumed for the various fractions: the most important composition information is the proportion of lignin and water in the fuel. The model should therefore give reasonable predictions of pyrolysis oil behaviour even if analyses are not available (as was the case in the present experiments). The same model could also be used for heavy fuel oil, which has very similar processes of evaporation and combustion [41, 42], simply by substituting properties sets for hydrocarbons instead of the chemical groups used here.

\section{Acknowledgements}

The authors are grateful for the financial support of the Natural Sciences and Engineering Research Council of Canada. 


\section{References}

[1] Shaddix C R, Tennison PR. Effects of char content and simple additives on biomass pyrolysis oil droplet combustion. $27^{\text {th }}$ Symposium (International) on Combustion, The Combustion Institute; 1998. p. 1907-1914.

[2] Shaddix CR, Hardesty DR. Combustion properties of biomass flash pyrolysis oils: final project report. Livermore, California: Sandia National Labs; 1999. Report SAND99-8238.

[3] Wornat MJ, Porter BG, Yang NYC. Single droplet combustion of biomass pyrolysis oils. Energy Fuels 1994; 8: 1131-1142.

[4] D’Alessio J, Lazzaro M, Massoli P, Moccia V. Thermo-optical investigation of burning biomass pyrolysis oil droplets. $27^{\text {th }}$ Symposium (International) on Combustion, The Combustion Institute; 1998. p. 1915-1922.

[5] Sipilä K, Kuoppala E, Fagernäs L, Oasmaa A. Characterization of biomass-based flash pyrolysis oils. Biomass Bioenergy 1998; 14: 103-113.

[6] Oasmaa A, Czernik S. Fuel oil quality of biomass pyrolysis oils - state of the art for the end users. Energy Fuels 1999; 13: 914-921.

[7] Oasmaa A, Kuoppala E, Gust S, Solantausta Y. Fast pyrolysis of forestry residue. 1. Effect of extractives on phase separation of pyrolysis liquids. Energy Fuels 2003; 17: 1-12.

[8] Oasmaa A, Kuoppala E, Solantausta Y. Fast pyrolysis of forestry residue. 2. Physicochemical composition of product liquid. Energy Fuels 2003; 17: 433-443.

[9] Oasmaa A, Kuoppala E. Fast pyrolysis of forestry residue. 3. Storage stability of liquid fuel. Energy Fuels 2003; 17: 1075-1084.

[10] Oasmaa A, Peacocke C. A guide to physical property characterization of biomass-derived fast 
pyrolysis liquids. Espoo, Finland: Technical Research Centre of Finland; 2001. VTT Publications 450. (available at http://www.vtt.fi/pro/pro2/pro22/indexe.htm ).

[11] Scholze B, Meier D. Characterization of the water-insoluble fraction from pyrolysis oil (pyrolytic lignin). Part I. Py-GC/MS, FTIR, and functional groups. J Anal Appl Pyrolysis 2001; 60: 41-54.

[12] Scholze B, Hanser C, Meier D. Characterization of the water-insoluble fraction from fast pyrolysis liquids (pyrolytic lignin). Part II. GPC, carbonyl groups, and ${ }^{13} \mathrm{C}-\mathrm{NMR}$. J Anal Appl Pyrolysis 2001; 58-59: 387-400.

[13] Branca C, Giudicianni P, Di Blasi C. GC/MS Characterization of liquids generated from lowtemperature pyrolysis of wood. Ind Eng Chem Research 2003; 42: 3190 - 3202.

[14] Evans RJ, Milne TA. Molecular characterization of the pyrolysis of biomass. 1. Fundamentals. Energy Fuels 1987; 1: 123-137.

[15] Maggi R, Delmon B. Characterization and upgrading of bio-oils produced by rapid thermal processing. Biomass Bioenergy 1994; 7: 245-249.

[16] Maggi R, Delmon B. Comparison between 'slow' and 'flash' pyrolysis oils from biomass. Fuel 1994; 73: 671-677.

[17] Boucher ME, Chaala A, Roy C. Bio-oils obtained by vacuum pyrolysis of softwood bark as a liquid fuel for gas turbines. Part I: Properties of bio-oil and its blends with methanol and a pyrolytic aqueous phase. Biomass Bioenergy 2000; 19: 337-350.

[18] Boucher ME, Chaala A, Pakdel H, Roy C. Bio-oils obtained by vacuum pyrolysis of softwood bark as a liquid fuel for gas turbines. Part II: Stability and ageing of bio-oil and its blends with methanol and a pyrolytic aqueous phase. Biomass Bioenergy 2000; 19: 351-361. 
[19] Ba T, Chaala A, Garcia-Perez M, Roy C. Colloidal properties of bio-oils obtained by vacuum pyrolysis of softwood bark. Storage stability. Energy Fuels 2004; 18: 188-201.

[20] Horne PA, Williams PT. Influence of temperature on the products from the flash pyrolysis of biomass. Fuel 1996; 75: 1051-1059.

[21] Alén R, Kuoppala E, Oesch P. Formation of the main degradation compound groups from wood and its components during pyrolysis. J Anal Appl Pyrolysis 1996; 36: 137-148.

[22] Shihadeh A, Hochgreb S. Impact of biomass pyrolysis oil process conditions on ignition delay in compression ignition engines. Energy Fuels 2002; 16: 552-561.

[23] Peacocke GVC, Russell PA, Jenkins JD, Bridgwater AV. Physical properties of flash pyrolysis liquids. Biomass Bioenergy 1994; 7: 169-177.

[24] Oasmaa A, Leppämäki E, Koponen P, Levander J, Tapola E. Physical characterisation of biomass-based pyrolysis liquids. Application of standard fuel oil analyses. Espoo, Finland: Technical Research Centre of Finland; 2001. VTT Publications 306. (available at http://www.vtt.fi/pro/pro2/pro22/indexe.htm ).

[25] Czernik S, Scahill J, Diebold JP. The production of liquid fuel by fast pyrolysis of biomass. ASME Journal Solar Energy Engineering 1995; 117: 2-6.

[26] Diebold JP, Czernik S. Additives to lower and stabilize the viscosity of pyrolysis oils during storage. Energy Fuels 1997; 11: 1081-1091

[27] Czernik S, Johnson DK, Black S. Stability of wood fast pyrolysis oil. Biomass Bioenergy 1994; 7: $187-192$.

[28] Czernik S, Bridgwater AV. Overview of applications of biomass fast pyrolysis oil. Energy Fuels 2004; 18: 590-598. 
[29] Tamim J, Hallett WLH. A continuous thermodynamics model for multicomponent droplet vaporization. Chemical Engineering Science 1995; 50: 2933-2942.

[30] Hallett WLH. A simple model for the vaporization of droplets with large numbers of components. Combust Flame 2000; 121: 334-344.

[31] Abdel-Qader Z, Hallett WLH. The role of liquid mixing in evaporation of complex multicomponent mixtures: modelling using continuous thermodynamics. Chemical Engineering Science 2005; 60: 1629-1640.

[32] Glassman I. Combustion, 2nd edition. New York: Academic Press; 1987.

[33] Newbold FR, Amundson NR. A model for evaporation of a multicomponent droplet. AIChE Journal 1973; 19: 22-30.

[34] Law CK, Law HK. A $d^{2}$ - law for multicomponent droplet vaporization and combustion. AIAA Journal 1981; 20: 522-527.

[35] Merrick D. Mathematical models of the thermal decomposition of coal. 2. Specific heats and heats of reaction. Fuel 1983; 62: 540-546.

[36] Órfão JJM, Antunes FJA, Figueiredo JL. Pyrolysis kinetics of lignocellulosic materials. Fuel 1999; 78: 349-358.

[37] Grønli MG, Varhegyi G, Di Blasi C. Thermogravimetric Analysis and Devolatilization Kinetics of Wood. Ind Eng Chem Research 2002; 41: 4201-4208.

[38] Avni E, Coughlin RW, Solomon PR, King HH. Mathematical modelling of lignin pyrolysis. Fuel 1985; 64: 1495-1501.

[39] Antal MJ, Varhegyi G. Cellulose pyrolysis kinetics: the current state of knowledge. Ind Eng Chem Research 1995; 34: 703-717. 
[40] Bergeron CA, Hallett WLH. Ignition characteristics of liquid hydrocarbon fuels as single droplets. Canadian J Chemical Engineering 1989; 67: 142-149.

[41] Chen CS, El-Wakil MM. Experimental and theoretical studies of burning drops of hydrocarbon mixtures. Proc Inst Mech Engineers 1969; 184 (Pt. 3J): 95-108.

[42] Braide KM, Isles GL, Jordan JB, Williams A. The combustion of single droplets of some fuel oils and alternative liquid fuel combinations. J Institute Energy 1979; 52: 115-124.

[43] Faulon J-L, Hatcher PG. Is there any order in the structure of lignin? Energy Fuels 1994; 8: 402407.

[44] Reid RC, Prausnitz JM, Poling BE. The properties of gases and liquids, 4th edition. New York: McGraw-Hill; 1987.

[45] Poling BE, Prausnitz JM, O’Connell JP. The properties of gases and liquids, 5th edition. New York: McGraw-Hill; 2001. 
Figure Captions

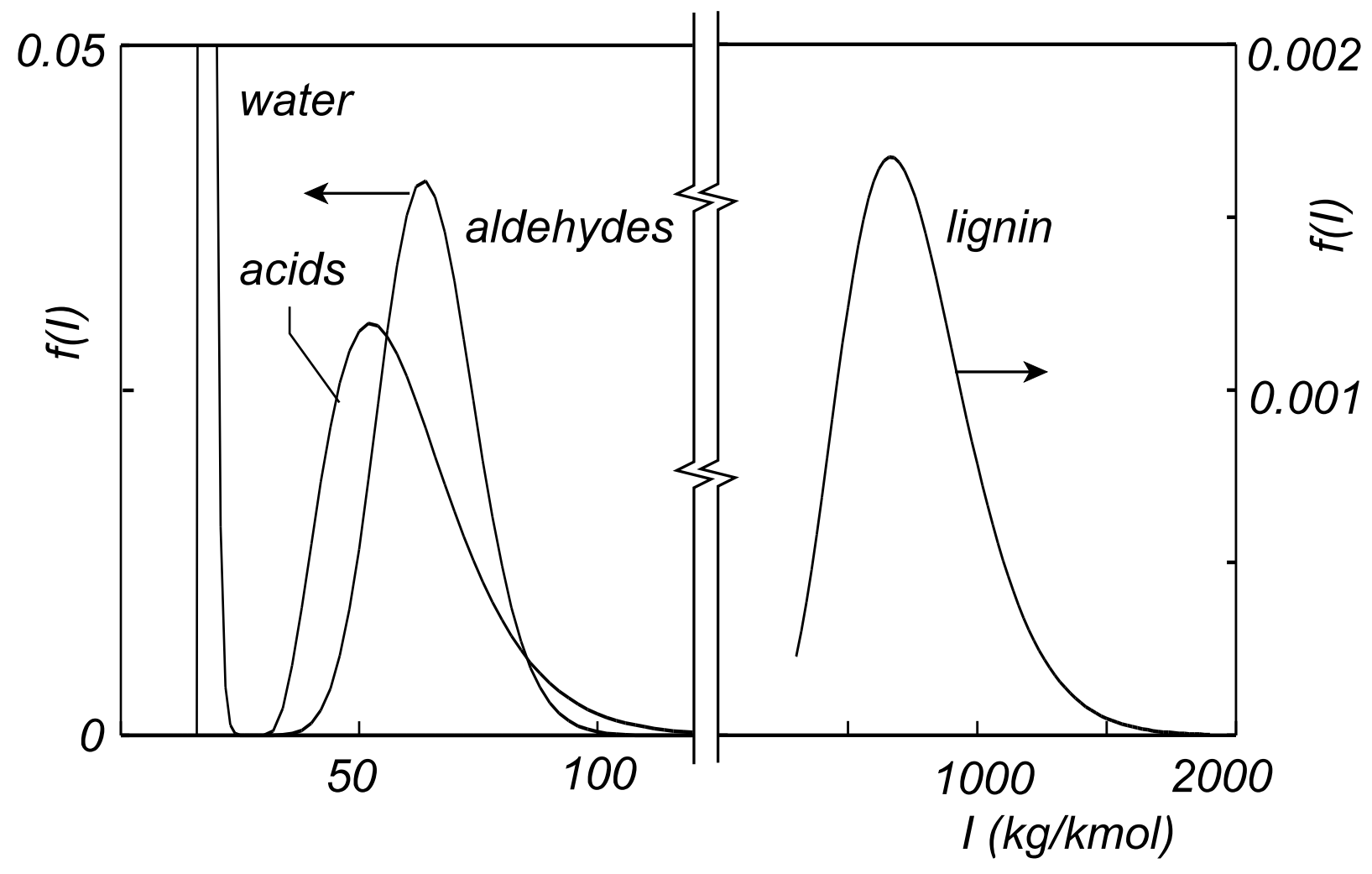

Fig. 1. Distribution functions used to simulate biomass pyrolysis oil. 


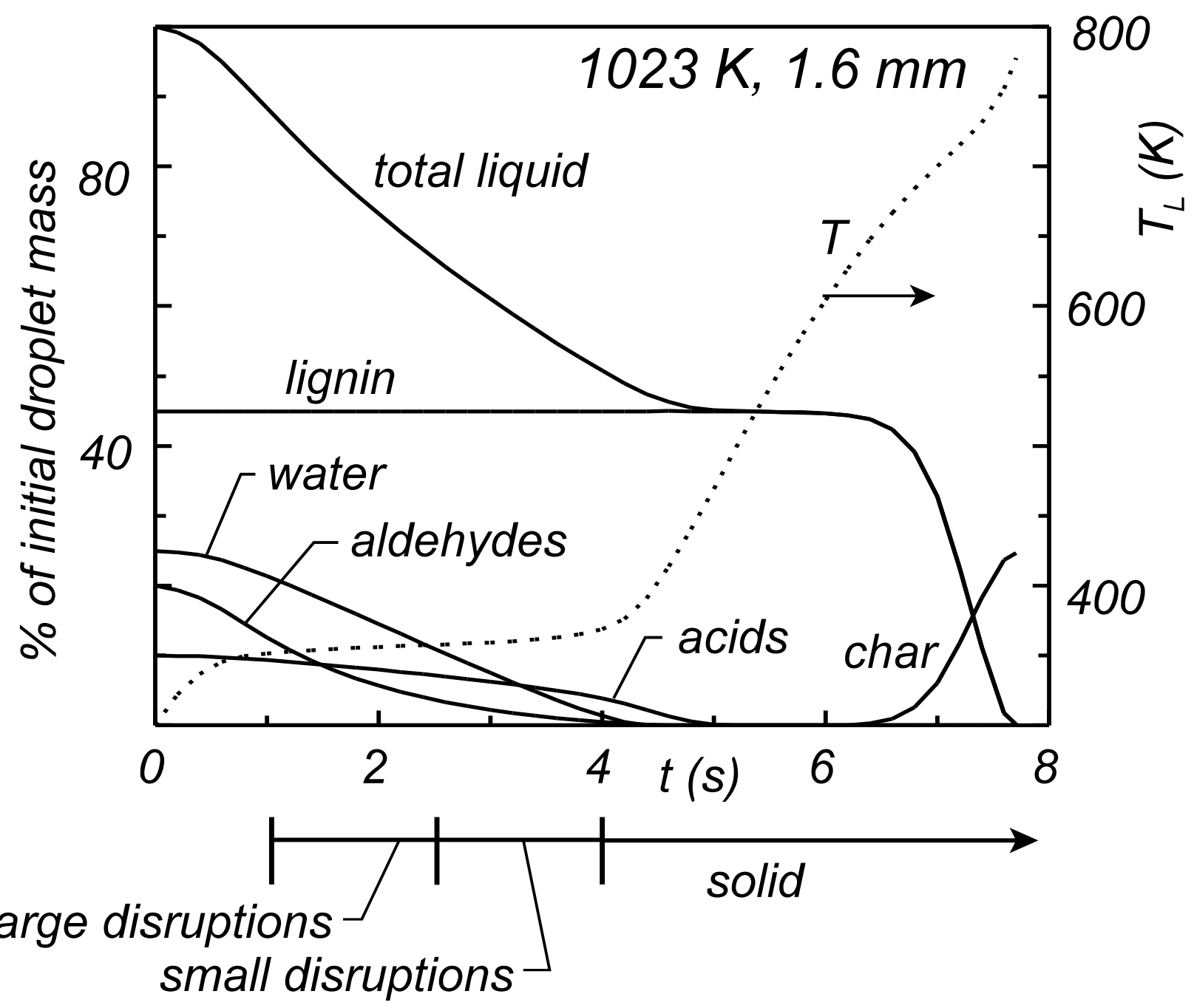

Fig. 2. Predicted droplet composition (expressed as fractions of initial droplet mass) and temperature as a function of time for a $1.6 \mathrm{~mm}$ pyrolysis oil droplet evaporating at $1023 \mathrm{~K}$. Observed droplet behaviour plotted below time scale. Initial droplet temperature 300K. 


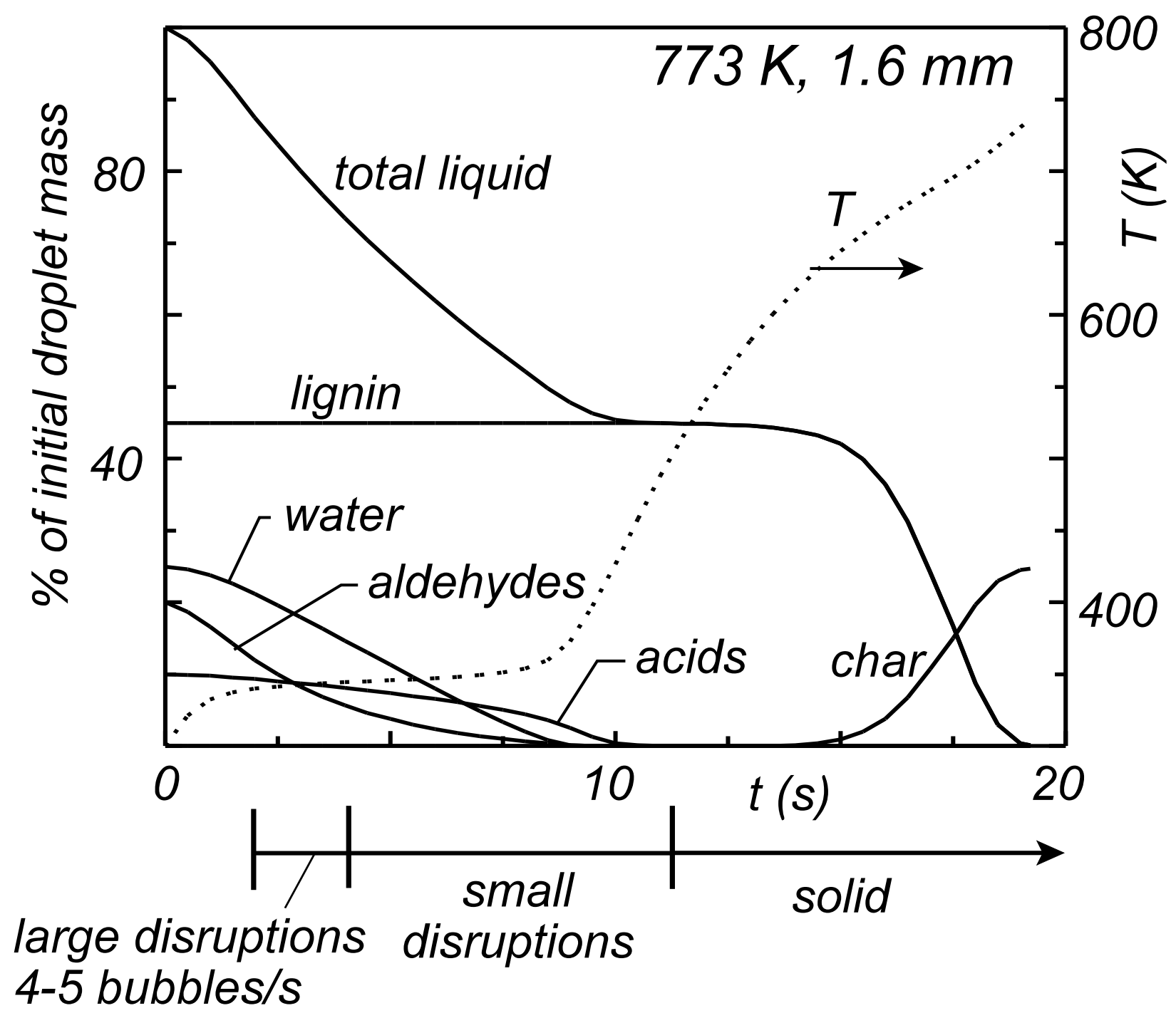

Fig. 3. Predicted droplet composition (expressed as fractions of initial droplet mass) and temperature as a function of time for a $1.6 \mathrm{~mm}$ pyrolysis oil droplet evaporating at $773 \mathrm{~K}$. Observed droplet behaviour plotted below time scale. Initial droplet temperature $300 \mathrm{~K}$. 


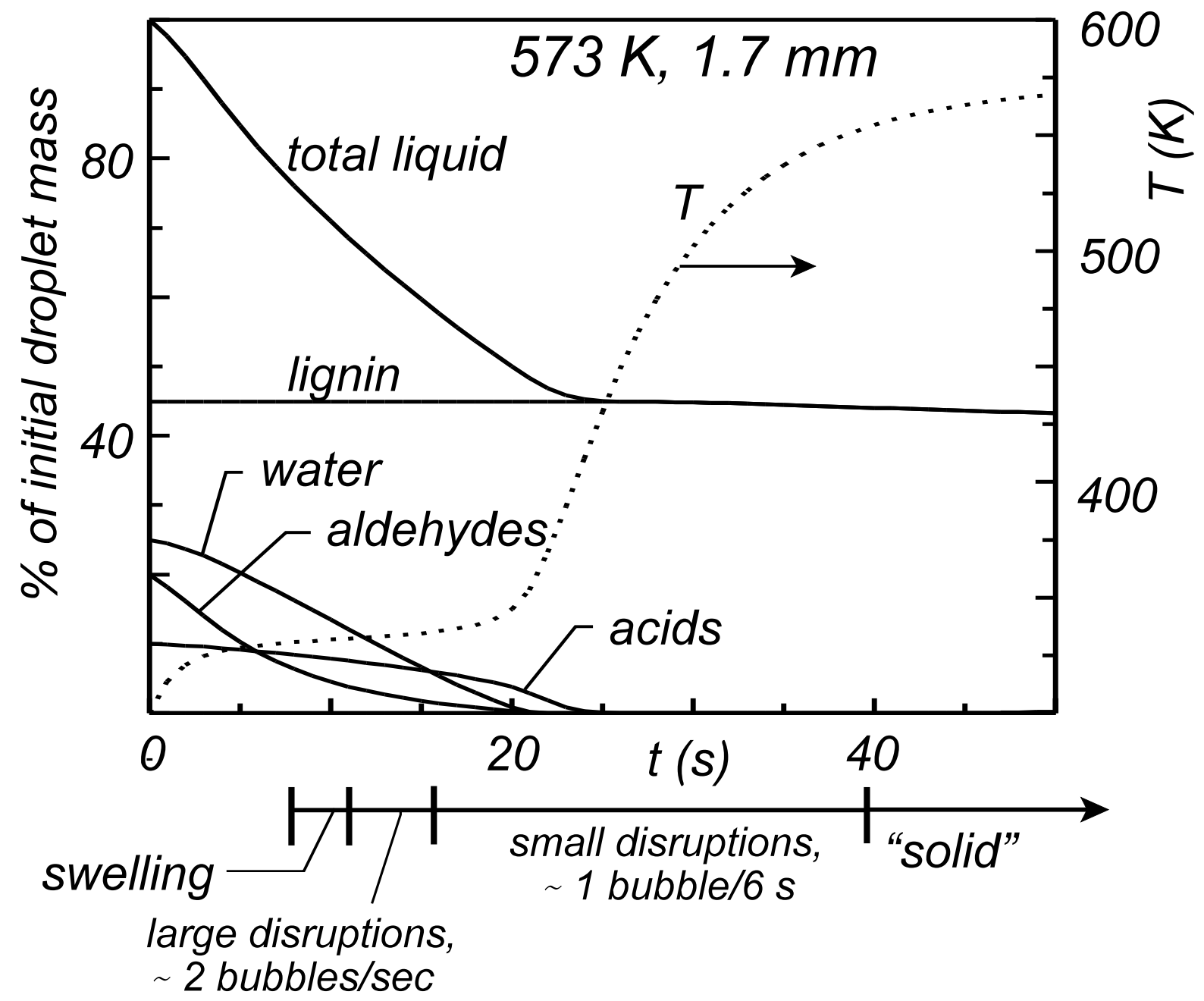

Fig. 4. Predicted droplet composition (expressed as fractions of initial droplet mass) and temperature as a function of time for a $1.7 \mathrm{~mm}$ pyrolysis oil droplet evaporating at $573 \mathrm{~K}$. Observed droplet behaviour plotted below time scale. Initial droplet temperature $300 \mathrm{~K}$. 


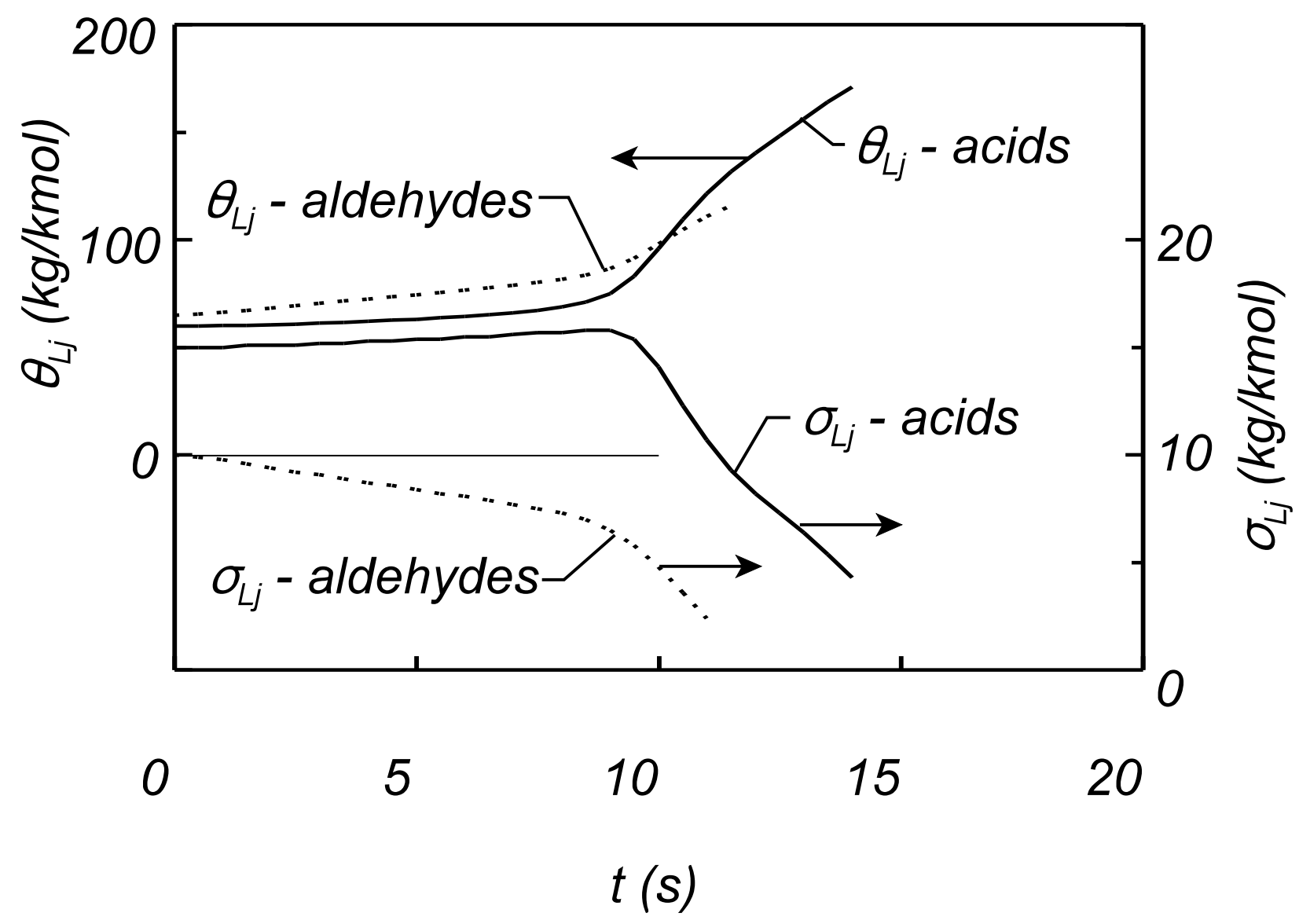

Fig. 5. Predicted acid and aldehyde fraction distribution parameters $\theta_{L}$ and $\sigma_{L}$ as functions of time for a $1.6 \mathrm{~mm}$ pyrolysis oil droplet evaporating at $773 \mathrm{~K}$. Initial droplet temperature $300 \mathrm{~K}$. 


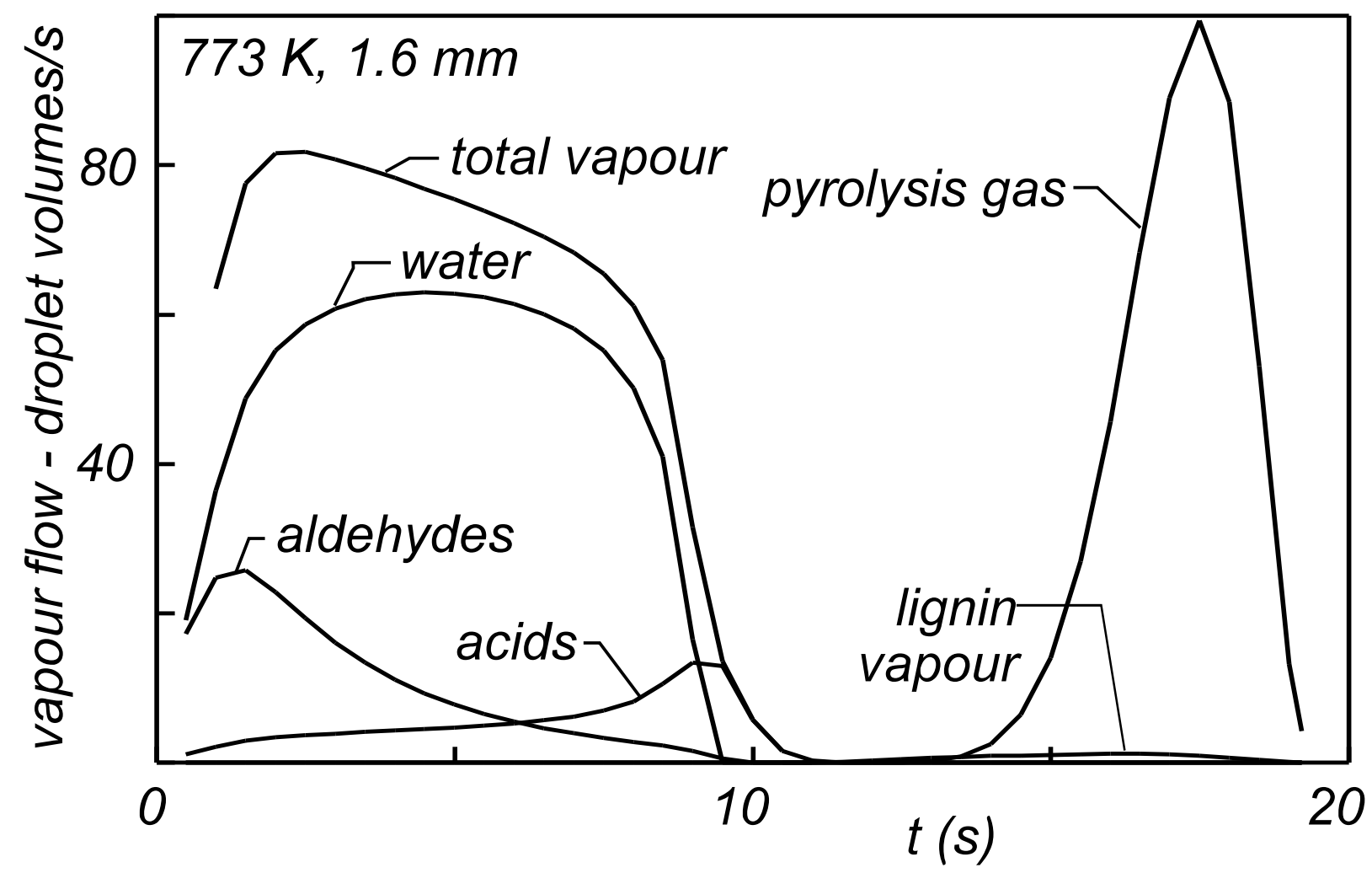

Fig. 6. Predicted vapour and pyrolysis gas evolution rates, expressed in initial droplet volumes per second, for a $1.6 \mathrm{~mm}$ pyrolysis oil droplet evaporating at $773 \mathrm{~K}$. Initial droplet temperature $300 \mathrm{~K}$. 


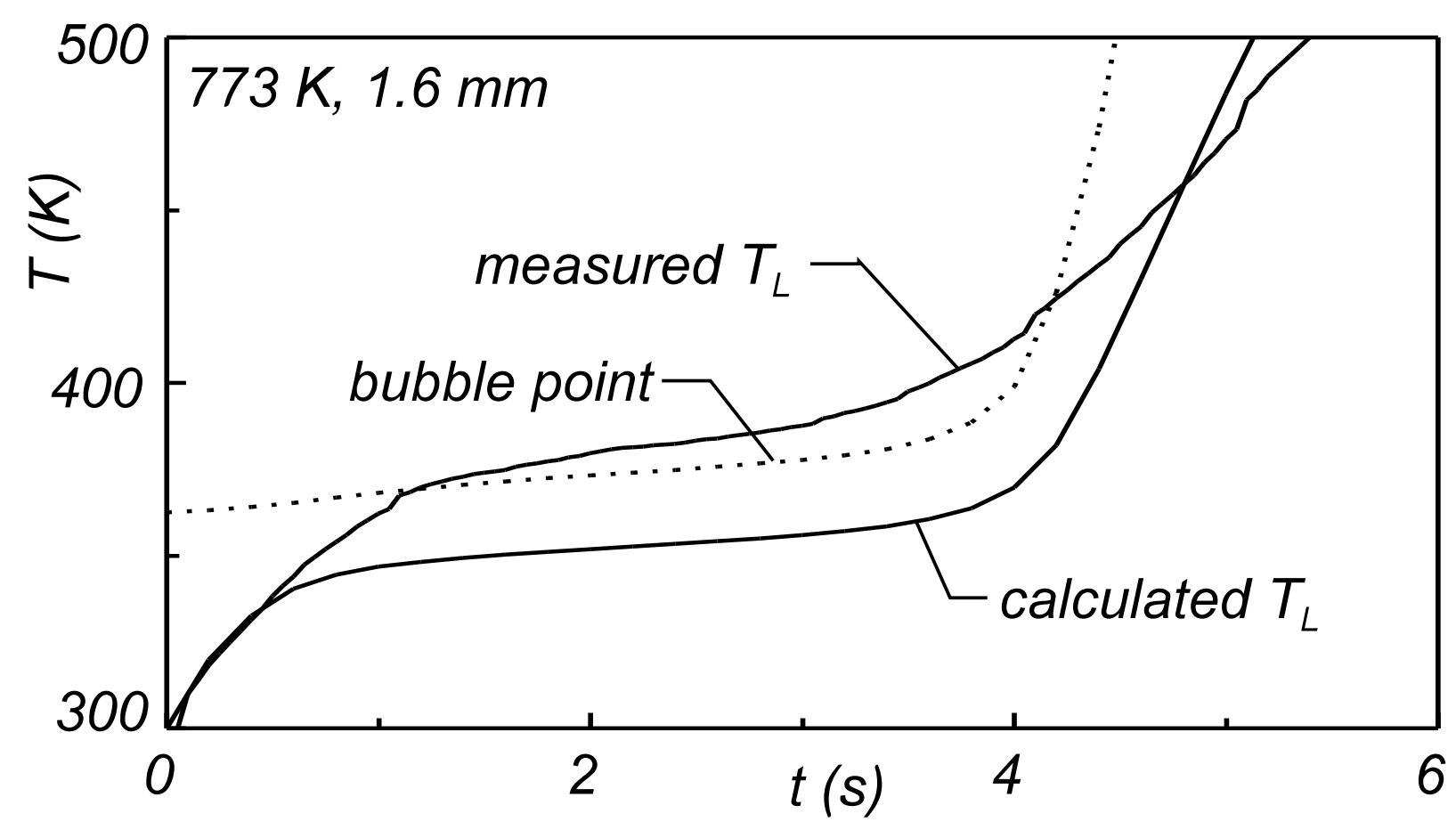

Fig. 7. Predicted droplet temperature and mixture bubble point compared with temperature measured by a $0.127 \mathrm{~mm}$ thermocouple supporting the droplet, for a $1.6 \mathrm{~mm}$ pyrolysis oil droplet evaporating at $773 \mathrm{~K}$. Initial droplet temperature $300 \mathrm{~K}$. The predictions include an estimate of the additional heat transfer to the droplet through the thermocouple. 


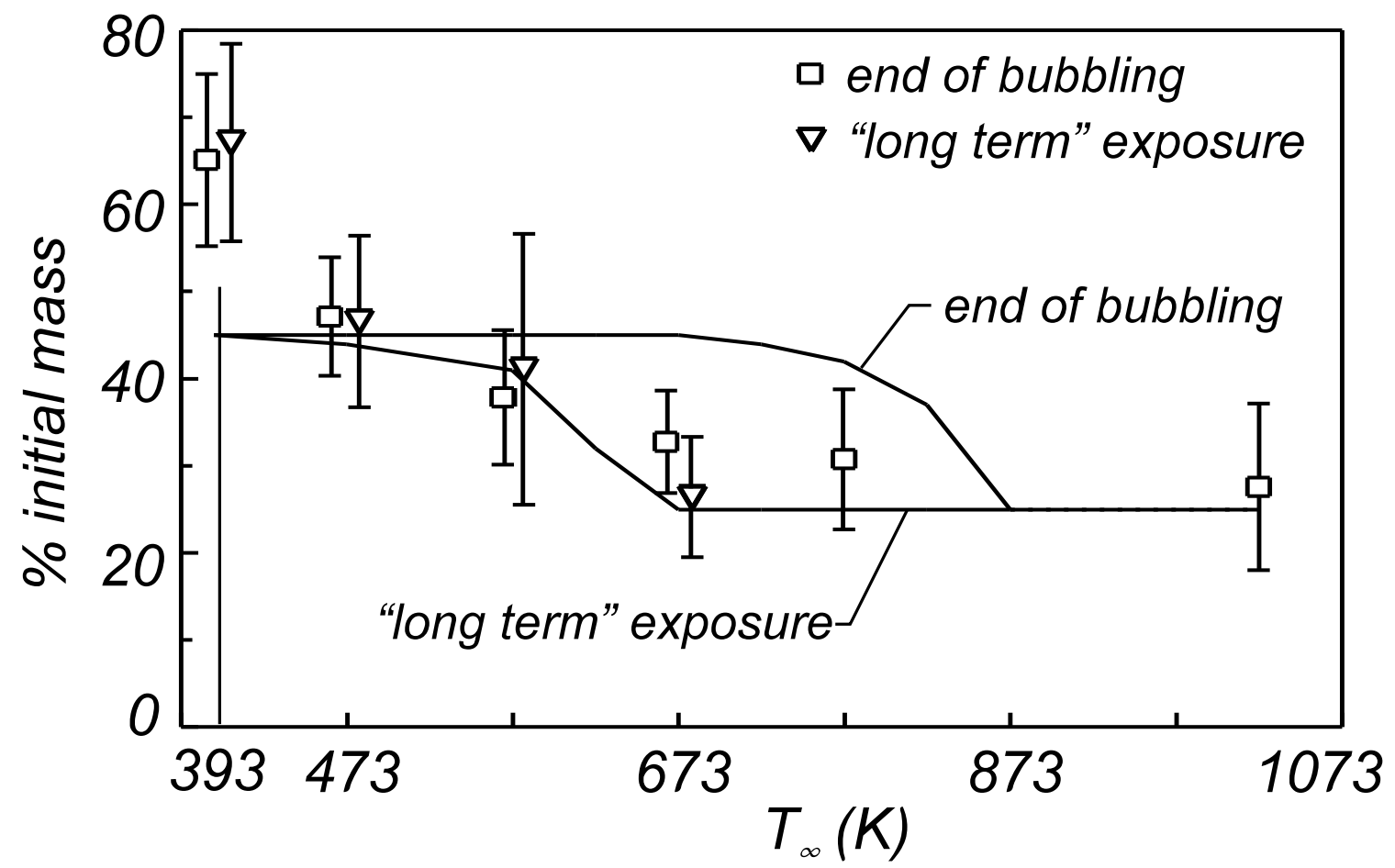

Fig. 8. Measurements of residue remaining after droplet evaporation and corresponding model predictions as a function of ambient temperature. Upper points and curves represent droplets withdrawn from the furnace shortly after bubbling ceased (defined arbitrarily as the time at which the light components disappeared plus 5 seconds for the predicted values), while lower points and curves represent a five times longer exposure to the furnace. Points are experimental, lines are predicted. Error bars represent standard deviation of data; each point is the result of 4-6 samples. 


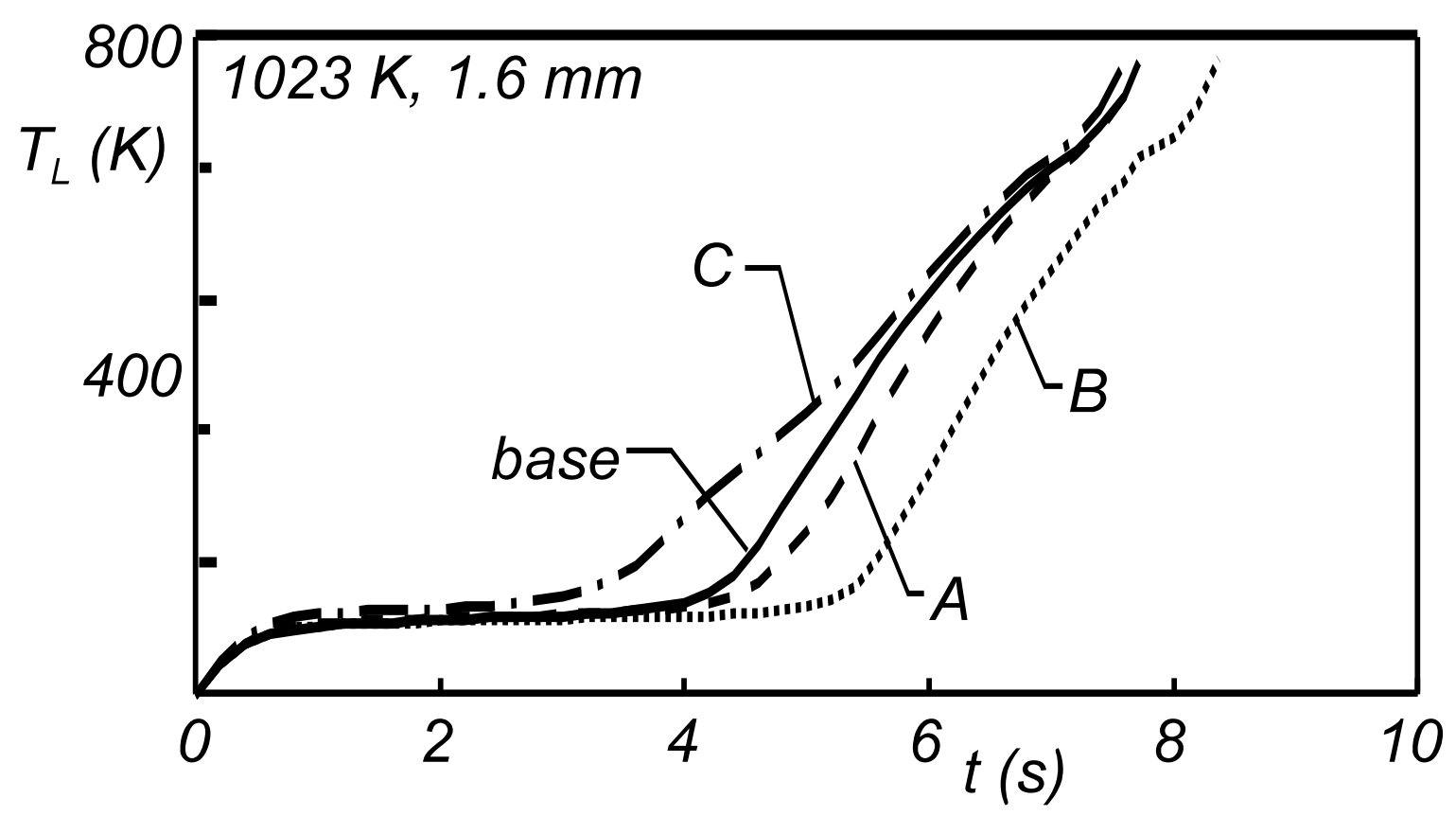

Fig. 9. Effects of variations in composition on the predicted droplet temperature for a $1.6 \mathrm{~mm}$ pyrolysis oil droplet evaporating at $1023 \mathrm{~K}$. Base $=$ composition of Table 1 ; $\mathrm{A}=$ acid fraction increased to $20 \%$, lignin decreased to $35 \%$; $\mathrm{B}=$ water fraction increased to $20 \%$, lignin decreased to $35 \% ; \mathrm{C}=$ base composition, but with $\theta_{\mathrm{L}}=130, \sigma_{\mathrm{L}}=20$ for the aldehyde fraction (double the original values). 


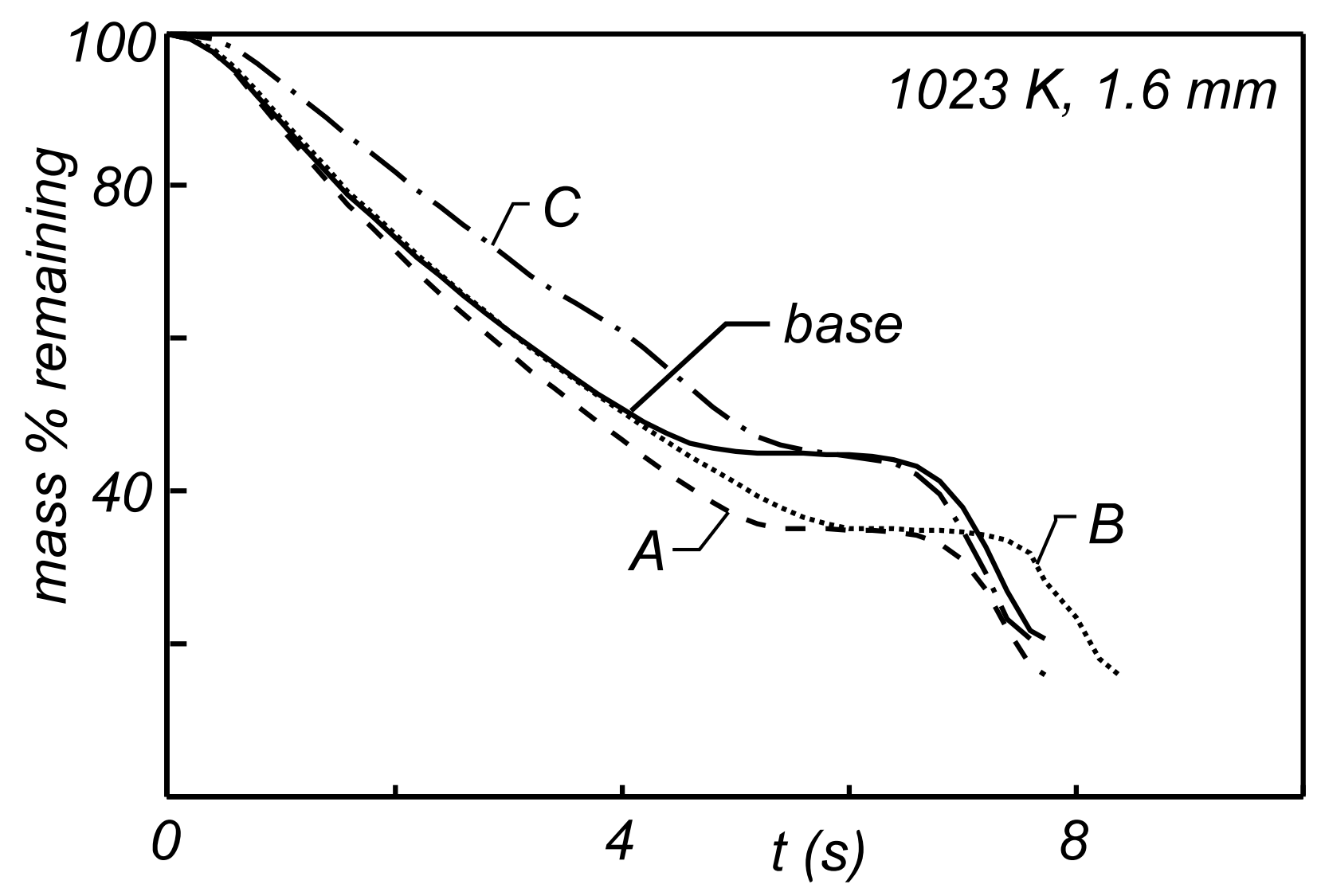

Fig. 10. Effects of variations in composition on the predicted droplet mass history for a $1.6 \mathrm{~mm}$ pyrolysis oil droplet evaporating at $1023 \mathrm{~K}$. Base $=$ composition of Table 1; $\mathrm{A}=$ acid fraction increased to $20 \%$, lignin decreased to $35 \%$; $\mathrm{B}=$ water fraction increased to $20 \%$, lignin decreased to $35 \% ; \mathrm{C}=$ base composition, but with $\theta_{\mathrm{L}}=130, \sigma_{\mathrm{L}}=20$ for the aldehyde fraction (double the original values). 


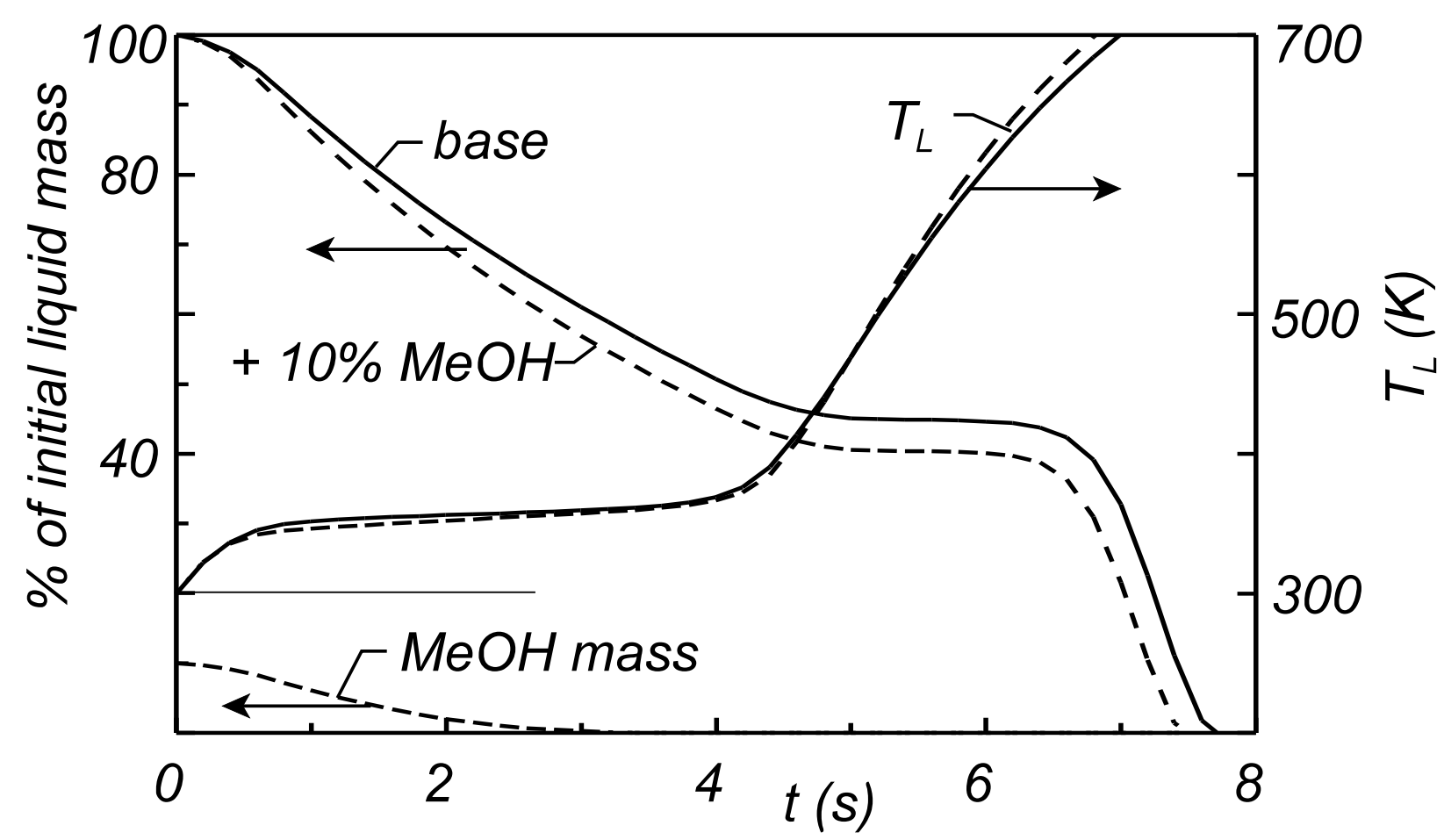

Fig. 11. Effect of adding 10\% methanol on the predicted droplet mass and temperature history for a $1.6 \mathrm{~mm}$ pyrolysis oil droplet evaporating at $1023 \mathrm{~K}$. Solid line $=$ base fuel (Table 1$)$, dashed line $=$ base fuel $+10 \% \mathrm{MeOH}$. 


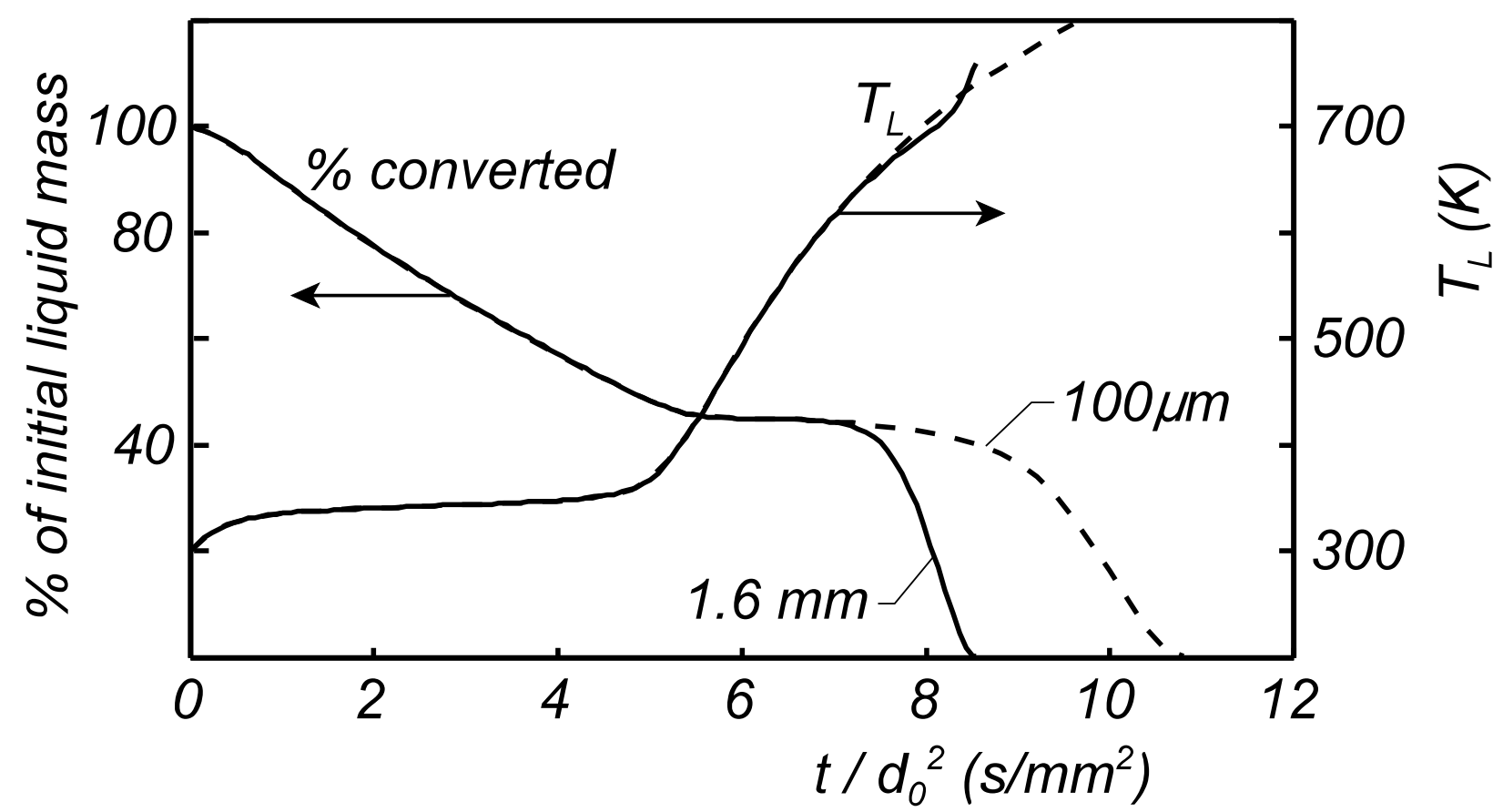

Fig. 12. Predicted droplet mass and temperature as a function of time for $1.6 \mathrm{~mm}$ (solid lines) and $100 \mu \mathrm{m}$ (dashed lines) droplets of pyrolysis oil evaporating at $1023 \mathrm{~K}$. Time axis scaled with $d_{0}^{2}$. Convection and radiation heat transfer not included (unlike all other figures). 
Table 1

Assumed Composition of Pyrolysis Oil

\begin{tabular}{|lll|l|l|}
\hline Component & mass fraction $\mathrm{w}_{\mathrm{i}}$ distribution & standard & distribution \\
& & mean $\theta_{\mathrm{L}}$ & deviation $\sigma_{\mathrm{L}}$ & origin $\gamma$ \\
\hline acids & 0.1 & 60 & 15 & 30 \\
\hline aldehydes/ & 0.2 & 65 & 10 & 0 \\
ketones & & 18 & & \\
\hline water & 0.25 & 750 & 1 & 16 \\
\hline pyrolytic lignin & 0.45 & & 250 & 0 \\
\hline
\end{tabular}




\section{Appendix - Properties of Fuel Constituents}

This Appendix details the calculation methods for the numerous properties required for the model equations.

\section{A.1 Development of Property Correlations}

The calculation of properties such as specific heat for a mixture of discrete components requires taking an appropriately weighted sum of the component properties. With a continuous distribution function these sums become integrals over the distribution function, and to evaluate these integrals properties of individual components must be provided as simple correlations preferably linear - with component molecular weight. The variation of properties with temperature must also be included, again in a reasonably simple algebraic form. Appropriate correlating equations were therefore developed for the required properties - vapour and liquid specific heat, vapour thermal conductivity and diffusivity, critical state, liquid density, boiling point, and enthalpy of vaporization - for each of the four chemical groups used to simulate the pyrolysis oil. The forms of the equations are the same as in earlier continuous mixture models [29-31], and are given in Section A.2 below, while Table A1 summarizes the coefficients required. The coefficients for each chemical group were determined by fitting to actual properties for representative members of that group, chosen as follows:

- for acids: formic, acetic, propanoic, $n$-butyric and $n$-valeric acids.

- for aldehydes and ketones: formaldehyde, acetaldehyde, propionaldehyde, $n$-butyraldehyde, and $n$ valeraldehyde.

- for "lignin" (comprising pyrolytic lignin, phenols and anhydrosugars): phenol, guaiacol, coniferyl alcohol, and a lignin dimer as shown by Faulon and Hatcher [43, Fig. 1 structure (5)]. 
Properties for alcohols were also generated for calculations with methanol-diluted oil, and for these the correlations were based on methanol, 1-propanol and 1-butanol.

Most properties for these compounds were available from tabulations [44, 45], but diffusivities and thermal conductivities for all species had to be estimated using Chapman-Enskog theory and the Stiel and Thodos form of the Eucken equation [44], and liquid specific heats were estimated using the Missenard method [44]. For the lignin group, excepting phenol, the following additional property estimation methods were used:

- critical state and boiling point: Constantinou-Gani group contribution method [45]

- vapour specific heat: Joback group contribution method [44]

- liquid specific heat: Ruzicka-Domalski group contribution method [45]

- enthalpy of vaporization: Chen corresponding states method [45].

The model requires a full set of property correlations for each group; however, for the lignin group the only properties of real significance are liquid specific heat and density, since very little of the lignin evaporates. The lignin density was set to $1800 \mathrm{~kg} / \mathrm{m}^{3}$ in order to force the mixture density to equal the value of $1.2 \mathrm{~kg} / \mathrm{m}^{3}$ cited by most researchers $[5,6,10,22-25]$. To prevent the occurrence of unreasonable values at large molecular weights, additional constraints were set such that diffusivities could not be less than that for $n$-hexadecane, thermal conductivities were $>0.01$, and critical pressures were $>10$ bar.

Gaseous products of pyrolysis were modelled as $\mathrm{CO}_{2}$, for which correlations are also listed in Table A1. 


\section{A.2 Correlating Equations}

Boiling point $(\mathrm{K}): \quad T_{B}=a_{B}+b_{B} I$

Critical temperature (K): $\quad T_{c r}=a_{c r}+b_{c r} I$

Critical pressure (atm): $\quad P_{c r}=a_{P}+b_{P} I$

Diffusion coefficient $\left(\mathrm{m}^{2} / \mathrm{s}\right.$, with T in K): $\quad \bar{D}=\left(a_{D}+b_{D} I\right) \frac{T^{5 / 2}}{b_{\Phi}+T}$

Thermal conductivity (W/m K, with T in K): $\quad \lambda=a_{K C}+a_{K T} T+\left(b_{K C}+b_{K T} T\right) I$

Vapour specific heat $\left(\mathrm{kJ} / \mathrm{kmol} \mathrm{K}\right.$, with T in K): $\quad C_{P}=a_{C P}+b_{C P} I$

$$
\text { where } a_{C P}=a_{C 0}+a_{C 1} T+a_{C 2} T^{2}+a_{C 3} T^{3} ; b_{C P}=b_{C 0}+b_{C 1} T+b_{C 2} T^{2}+b_{C 3} T^{3}
$$

Enthalpy of vaporization $(\mathrm{J} / \mathrm{kmol}$, with $\mathrm{T}$ in $\mathrm{K})$ :

$$
h_{f g}=\Phi_{H}\left(a_{H}+b_{H} I\right) ; \quad \Phi_{H}=\left(\frac{T_{c r}-T}{T_{c r}-T_{B}}\right)^{0.38}
$$

Liquid specific heat $\left(\mathrm{kJ} / \mathrm{kmol} \mathrm{K}\right.$, with T in K): $\quad C_{P L}=\left(a_{L}+b_{L} T+c_{L} T^{2}\right) I$

\section{A.3 Mixture Properties}

Mixture properties are developed from these correlations. The fuel vapour specific heat integral given in [31] becomes, with the correlating equation for $C_{P}$ given above:

$$
C_{P G}=\sum_{j=1}^{J} y_{F j}\left(a_{C P j}+b_{C P j} \theta_{R E F j}\right)+y_{G}\left(a_{C P G}+b_{C P G} \theta_{G}\right)
$$

where $\theta_{\mathrm{REF}}$ is the mean of distribution $j$ evaluated at the properties reference state (see Section A.4 below). The last term represents pyrolysis gas, with $y_{G}$ determined using eq. (7). The liquid specific heat is likewise 


$$
C_{P L}=\sum_{j=1}^{J} x_{F j}\left(a_{L j}+b_{L j} T+c_{L j} T^{2}\right) \theta_{L j}
$$

The vapour phase thermal conductivity $\lambda$ is defined by using the Mason-Saxena rule $[29,44]$ to combine the conductivity of air with the conductivity $\lambda_{\mathrm{G}}$ of the fuel vapour and pyrolysis gas mix, approximated as

$$
\begin{aligned}
\lambda_{G}=\sum_{j=1}^{J} y_{F j}\left(a_{K C j}+a_{K T j} T+\left(b_{K C j}+b_{K T j} T\right) \theta_{R E F j}\right) \\
+y_{G}\left(a_{K C G}+a_{K T G} T+\left(b_{K C G}+b_{K T G} T\right) \theta_{G}\right)
\end{aligned}
$$

The multi-distribution form of the enthalpy of vaporization given in [31] with the $\mathrm{h}_{\mathrm{fg}}$ correlation given above can be simplified for the quasi-steady solution as in [30] to give

$$
h_{f g}=\sum_{j=1}^{J} \Phi_{H j}\left\{a_{H j} \chi_{j}+\frac{b_{H j}}{B_{j}}\left[\theta_{R j} y_{F R j}\left(1+B_{j}\right)-\theta_{\infty j} y_{F \infty}\right]\right\}
$$

Finally, the diffusivity $\bar{D}_{j}$ for fraction $j$ is simply the expression for $D$ with $\theta_{\mathrm{REF}}$ substituted for I.

\section{A.4 Reference State}

All vapour phase properties except $h_{f g}$ were evaluated at a reference state defined as [30]:

$$
\begin{aligned}
& T_{R E F}= \frac{2}{3} T_{R}+\frac{1}{3} T_{\infty} ; y_{F R E F j}=\frac{2}{3} y_{F R j}+\frac{1}{3} y_{F \infty j} ; \\
& \theta_{R E F j}=\left(\frac{2}{3} y_{F R j} \theta_{R j}+\frac{1}{3} y_{F \infty j} \theta_{\infty j}\right) / y_{F R E F j}
\end{aligned}
$$


Table A1: Coefficients for Properties Correlations

\begin{tabular}{|c|c|c|c|c|c|c|}
\hline & acids & $\begin{array}{l}\text { aldehydes, } \\
\text { ketones }\end{array}$ & water & alcohols & "lignin" & $\begin{array}{l}\text { pyrolysis gas } \\
\left(\mathrm{CO}_{2}\right)\end{array}$ \\
\hline$a_{B}$ & 300 & 195.1 & 373 & 293.1 & 346.9 & - \\
\hline$b_{B}$ & 1.55 & 2.126 & 0 & 1.33 & 1.097 & - \\
\hline $\mathrm{s}_{\mathrm{fg}}(\mathrm{kJ} / \mathrm{kmol} \mathrm{K})$ & 101 & 90 & 109 & 115 & 87.9 & - \\
\hline$a_{c r}$ & 519.1 & 340.8 & 647.3 & 460 & 630 & 304.2 \\
\hline$b_{\text {cr }}$ & 1.26 & 2.685 & 0 & 1.435 & 0.841 & 0 \\
\hline$a_{P}$ & 94.74 & 85.08 & 221.2 & 92.327 & 60 & 72.9 \\
\hline$b_{P}$ & -0.542 & -0.504 & 0 & -0.585 & -0.128 & 0 \\
\hline$a_{D}$ & $5.61 \mathrm{e}-09$ & $6.14 \mathrm{e}-09$ & $6.55 \mathrm{e}-09$ & $5.60 \mathrm{e}-09$ & $3.19 \mathrm{e}-09$ & $4.99 e-09$ \\
\hline $\mathrm{b}_{\mathrm{D}}$ & $-3.05 e-11$ & $-4.30 \mathrm{e}-11$ & 0 & $-3.26 \mathrm{e}-11$ & $-5.12 \mathrm{e}-12$ & 0 \\
\hline $\mathrm{b}_{\Phi}$ & 220 & 200 & 240 & 210 & 245 & 220 \\
\hline $\mathrm{a}_{\mathrm{KC}}$ & -0.01491 & -0.01192 & -0.0063 & $-2.23 e-02$ & -0.02405 & $-2.55 e-05$ \\
\hline $\mathrm{a}_{\mathrm{KT}}$ & $9.37 \mathrm{e}-05$ & $9.61 \mathrm{e}-05$ & $8.00 \mathrm{e}-05$ & $1.23 \mathrm{e}-04$ & $1.03 \mathrm{e}-04$ & $5.92 \mathrm{e}-05$ \\
\hline $\mathrm{b}_{\mathrm{KC}}$ & $-4.29 \mathrm{e}-05$ & $-1.09 \mathrm{e}-04$ & 0 & $-1.36 e-05$ & $3.34 \mathrm{e}-05$ & 0 \\
\hline $\mathrm{b}_{\mathrm{KT}}$ & $4.90 \mathrm{e}-09$ & $7.56 \mathrm{e}-08$ & 0 & $-1.35 e-07$ & $-1.23 e-07$ & 0 \\
\hline $\mathrm{a}_{\mathrm{C} 0}$ & 4.066 & 32.76 & 32.34 & 34.42 & -75.39 & 22.11 \\
\hline
\end{tabular}




\begin{tabular}{|c|c|c|c|c|c|c|}
\hline$a_{\mathrm{C} 1}$ & -0.1397 & -0.202 & 0.001921 & -0.191 & 0.3572 & 0.05953 \\
\hline $\mathrm{a}_{\mathrm{C} 2}$ & $4.12 \mathrm{e}-05$ & $1.84 \mathrm{e}-04$ & $1.06 \mathrm{e}-05$ & $2.14 \mathrm{e}-04$ & $-5.11 \mathrm{e}-04$ & $-3.46 e-05$ \\
\hline $\mathrm{a}_{\mathrm{C} 3}$ & $6.38 \mathrm{e}-09$ & $-6.21 \mathrm{e}-08$ & $-3.60 e-09$ & $-8.48 \mathrm{e}-08$ & $2.42 \mathrm{e}-07$ & $7.30 \mathrm{e}-09$ \\
\hline $\mathrm{b}_{\mathrm{C} 0}$ & 0.07458 & -0.4199 & 0 & -0.46 & 0.3147 & 0 \\
\hline $\mathrm{b}_{\mathrm{C} 1}$ & $6.52 \mathrm{e}-03$ & $8.18 \mathrm{e}-03$ & 0 & $8.40 \mathrm{e}-03$ & $3.22 \mathrm{e}-03$ & 0 \\
\hline $\mathrm{b}_{\mathrm{C} 2}$ & $-3.55 e-06$ & $-5.69 \mathrm{e}-06$ & 0 & $-6.17 \mathrm{e}-06$ & $-9.88 \mathrm{e}-07$ & 0 \\
\hline $\mathrm{b}_{\mathrm{C} 3}$ & $7.14 \mathrm{e}-10$ & $1.58 \mathrm{e}-09$ & 0 & $1.90 \mathrm{e}-09$ & $-1.74 \mathrm{e}-10$ & 0 \\
\hline $\mathrm{a}_{\mathrm{H}}$ & $2.66 \mathrm{e}+07$ & $1.72 \mathrm{e}+07$ & $4.07 \mathrm{e}+07$ & $3.01 \mathrm{e}+07$ & $3.35 \mathrm{e}+07$ & - \\
\hline $\mathrm{b}_{\mathrm{H}}$ & $2.36 \mathrm{e}+05$ & $1.93 \mathrm{e}+05$ & 0 & $1.76 \mathrm{e}+05$ & $1.28 \mathrm{e}+05$ & - \\
\hline$\left(\mathrm{T}_{\mathrm{cr}}-\mathrm{T}_{\mathrm{B}}\right)^{0.38}$ & 7.42735 & 7.10125 & 8.442 & 7.1074 & 7.856 & - \\
\hline$a_{L}$ & 0.7012 & 2.673 & 5.312 & 3.12 & 0.9239 & - \\
\hline $\mathrm{b}_{\mathrm{L}}$ & 0.00412 & -0.005774 & -0.00739 & -0.0122 & 0.004166 & - \\
\hline $\mathrm{c}_{\mathrm{L}}$ & $8.80 \mathrm{e}-07$ & $1.40 \mathrm{e}-05$ & $1.18 \mathrm{e}-05$ & $3.33 e-05$ & 0 & - \\
\hline $\begin{array}{l}\rho_{\mathrm{L}}\left(\mathrm{kg} / \mathrm{m}^{3}\right) \text { at } \\
20^{\circ} \mathrm{C}\end{array}$ & 1117 & 809 & 1000 & 792 & 1800 & - \\
\hline
\end{tabular}

